Universidade de São Paulo

Faculdade de Economia, Administração e Contabilidade DE Ribeirão PREto

Departamento de Economia

KÁtia Morinaga Honda

\title{
Um Estudo sobre os Determinantes do Atraso Escolar
}

Ribeirão Preto

2007 
Reitora: Prof ${ }^{a}$ Dr $^{\text {a }}$ Suely Vilela

Diretor da faculdade: Prof. Dr. Rudinei Toneto Júnior Chefe do departamento de economia: Prof ${ }^{a}$ Dr $^{a}$ Maria Christina Siqueira de Souza Campos 
KÁTIA MORINAGA HONDA

\section{Um Estudo sobre os Determinantes do Atraso Escolar}

Dissertação Apresentada ao Departamento de Economia, Faculdade de Economia, Administração e Contabilidade de Ribeirão Preto da Universidade de São Paulo, para a obtenção do título de Mestre em Economia Aplicada.

Orientador: Prof. Dr. Walter Belluzzo Jr.

Ribeirão Preto 


\section{FICHA CATALOGRÁFICA}

Honda, Kátia Morinaga

Um estudo sobre os determinantes do atraso escolar.

Ribeirão Preto, 2006.

80 p. : il. ; 30cm

Tese de Mestrado, apresentada à Faculdade de Economia, Administração e Contabilidade de Ribeirão Preto/USP. Área de concentração: Economia Aplicada

Orientador: Belluzzo Jr, Walter

1. Atraso escolar 2. Capital humano 3.Características familiares 4. Variável endógena 5.quase-verossimilhança em dois estágios 


\title{
Folha de Aprovação
}

Kátia Morinaga Honda

Um Estudo sobre os Determinantes

do Atraso Escolar

Dissertação Apresentada ao Departamento de Economia, Faculdade de Economia, Administração e Contabilidade de Ribeirão Preto da Universidade de São Paulo, para a obtenção do título de Mestre em Economia Aplicada.

Aprovada em:

\section{Banca Examinadora}

Prof. Dr. Walter Belluzzo Jr.

Orientador

\author{
Prof. Dra. Elaine Toldo Pazzelo \\ Universidade de São Paulo
}




\section{DEDICO:}

aos meus pais,

à Cíntia,

ao Hélio.

\section{OFEREÇO}

ÀS

FAMÍLIAS:

Honda

Morinaga

Sueyoshi 


\section{Agradecimentos}

\section{Este trabalho não teria sido possível:}

- Sem a presença de pessoas especiais. Muitas pessoas contribuíram para a realização desse trabalho e não posso deixar de agradecer:

- Ao meu orientador, que com sabedoria e paciência me ensinou a trabalhar de forma consciente os números e os métodos econométricos. Um exemplo a ser seguido, de esforço, de competência, de inteligência e de trabalho. E que compartilhou todo o seu grande conhecimento, não só na área econômica, como também na vida.

- À professora Elaine pelas idéias, pelas correções e sugestões no meu exame de qualificação. E principalmente, pela ajuda, pela atenção e pelo carinho em todos os momentos, nos mais difíceis ajudou a superar as barreiras e solucionar os problemas. Excelente professora, sempre atenciosa com todos os seus alunos, um exemplo a ser seguido.

- À professora Maria Dolores, pelas idéias e sugestões no meu exame de qualificação, que foram de grande contribuição para o prosseguimento desta pesquisa.

- Ao professor Francisco, coordenador do curso durante o primeiro ano, que sempre estava disposto a escutar nossas reclamações e pronto a solucioná-las.

- À professora Cidinha e ao professor Guena, por transmitir de forma tão didática os conhecimentos mais avançados e pela forma carinhosa que sempre trataram seus alunos.

- Aos funcionários da FEA-RP e ao Departamento de Economia, pelo acolhimento e pela a disponibilidade de infra-estrutura para a pesquisa.

- Ao Departamento de Pós-Graduação Economia, especialmente ao Eduardo e a Érika que sempre cuidaram dos prazos e das informações necessárias para o prosseguimento do curso. 
- Aos meus amigos e colegas de classe: Carol, Carlos, Du, Gedir, Juliana, Mazinha, Renan, Renata, Sabrina, Victor e Vagner.

- Às minhas queridas amigas: Carolina, Juliana e Sabrina, que foram a minha família em Ribeirão Preto. Que me aguentaram e me apoiaram em todos os momentos, dos mais alegres ao mais difíceis, nunca me senti tão bem. Obrigada! Tenho vocês no coração.

- Aos meus pais que sempre acreditaram em mim. A minha mãe que sempre presente me ajudou a construir nossos sonhos. Ao meu pai, que com a sua sabedoria e justiça nos ensinou o significado da vida.

- A minha irmã, minha melhor amiga, que sempre carinhosamente me apoio em todo o processo. Até nos últimos parágrafos, estava ao meu lado me incentivando.

- Ao Hélio e sua família, que sempre me acolheram e me apoiaram de forma tão carinhosa e verdadeira. Ao meu amor, que compreendeu a minha ausência e sempre me apoiou e acreditou no meu potencial. Te amo!

- Aos meus primos: Érica, Victor,Cris e Paty, que sempre presentes em minha vida me ajudaram a trilhá-la.

- Aos meus amigos da graduação e do colegial (Thomas, Otávio, Lia, Laura e Mana), que entenderam a minha ausência e mesmo com a distância me apoiaram e nunca se esqueceram de mim.

- E o apoio financeiro da CAPES - Coordenação de Aperfeiçoamento de Pessoal de Nível Superior, Ministério da Educação 


\section{Resumo}

O objetivo desse trabalho é verificar a influência das características familiares no atraso escolar. O atraso escolar no Brasil, além de onerar os gastos do governo, representa baixo nível de capital humano acumulado nas crianças. Baixos níveis de capital humano acumulado representam indivíduos com habilidades mal desenvolvidas que atingem baixos níveis de produtividade dificultando o processo de desenvolvimento sustentável do país. O capital humano acumulado é resultado de um processo construtivo que depende do desenvolvimento do indivíduo no período anterior, portanto melhores desempenhos futuros são resultados de maior acúmulo de capital humano. A característica do processo sugere grande influência das características familiares. A família é o principal responsável por fornecer recursos durante os primeiros anos do processo de acúmulo de capital humano. O método utilizado para estimar o atraso escolar foi a quase verossimilhança em dois estágios, devido à natureza de contagem e à presença da variável endógena. O resultado obtido mostrou a influência da educação da mãe e do pai de forma a diminuir o atraso escolar e a diferença em magnitude em relação às estimações padrão. A variável renda, nesse método, apresentou impacto favorável ao atraso escolar.

Palavras-chave: atraso escolar, capital humano, características familiares, variável endógena e quase-verossimilhança em dois estágios 


\section{Abstract}

The objective of this thesis is to verify the influence of family characteristics in schooling delay. The schooling delay in Brazil increases government's spent and implies lower rate human capital accumulation on children. Lower rates of human capital accumulation means children will grow into less skilled workers, with low levels of productivity, which has a negative effect on development. The accumulation of human capital is a process that depends of the individual's development throughout her life. The study considers family factors that have an evident influence in children development, reinforcing that the family is one of the main sources in the process of accumulative human capital. The variable used as proxy to human capital accumulation was schooling delay, which is a count variable and is clearly to endogeneity. The approach in this thesis is referred to as the two-stage quasi likelihood. Results obtained indicate that Parent's education have a negative effect in the child's being behind at school, while household income has a positive effect. Additionally, the difference in magnitude when compared with standard estimation methods is significant.

Keywords: schooling delay, human capital, family features, endogenous variable and two-stage quase likelihood 


\section{Sumário}

Lista de Tabelas

Lista de Figuras

1 Introdução

2 Atraso escolar e educação no Brasil

3.1 Modelos Teóricos . . . . . . . . . . . . . . . . . . . 21

3.1.1 Modelo sem transferência . . . . . . . . . . . . . . . 23

3.1.2 Modelo com transferência . . . . . . . . . . . . . . 25

3.1.3 Transferências monetárias de pais pobres . . . . . . . . . . . 27

3.2 Modelos Empíricos . . . . . . . . . . . . . . . . . . . . . 29

3.3 Outras perspectivas . . . . . . . . . . . . . . . 33

4 Métodos Econométricos $\quad 35$

4.1 Modelo de Regressão de Poisson . . . . . . . . . . . . . . . . . . . 35

4.2 Testes para heteroscedasticidade, endogeneidade e sobreidentificação . . . . . . . . . . . . . . . 38

4.3 Método de variáveis instrumentais . . . . . . . . . . . . . . . . 43 
4.4 Alternativas para o modelo de Poisson . . . . . . . . . . . . . . . 45

4.5 Estimação por Quase Verossimilhança

em dois estágios . . . . . . . . . . . . . . . . . . . . . . . 47

4.6 Modelos de contagem modificados:

Modelo Hurdle que segue zeros inflados . . . . . . . . . . . . . . . . . . . . 48

5 Resultados Empíricos $\quad 51$

5.1 Descrição dos Dados . . . . . . . . . . . . . . . . . . . . 51

5.2 Resultados das estimações . . . . . . . . . . . . . . . . . . . . . 62

5.2.1 O Modelo Linear Simples . . . . . . . . . . . . . . . . . 62

5.2 .2 Teste de endogeneidade . . . . . . . . . . . . . . . . 64

5.2.3 O Modelo com dados em contagem . . . . . . . . . . . . . . . 68

6 Conclusão $\quad 74$

$\begin{array}{ll}\text { Referências } & 76\end{array}$ 


\section{Lista de Tabelas}

1 Descrição das variáveis do estudo . . . . . . . . . . . . . . . . . . . 54

2 Distribuição das variáveis qualitativas entre regiões . . . . . . . . . . . 57

3 Características do Atraso Escolar . . . . . . . . . . . . . . . . . . 60

4 Características sociais médias condicionada ao nível de escolaridade da mãe 61

5 Estimação do atraso escolar - MQO . . . . . . . . . . . . . . . 63

6 Estimação da variável e do resíduo da educação da mãe - Primeiro estágio 65

$7 \quad$ Teste de endogeneidade - para a variável educação da mãe $\quad \ldots$. . . . . . . . 66

8 Estimação da variável e do resíduo da educação do pai - Primeiro estágio 67

9 Teste de endogeneidade - para a variável educação do pai . . . . . . . . . 68

10 Estimação da variável e do resíduo da renda familiar - Primeiro estágio . . 69

11 Teste de endogeneidade - para a variável renda familiar . . . . . . . . . . . 70

12 Teste de endogeneidade conjunta, heteroscedasticidade e sobreidentificação 70

13 Modelo de Poisson . . . . . . . . . . . . . . . . . . . . . . 71

14 MQ2E X QML X ML . . . . . . . . . . . . . . . . . . 73 


\section{Lista de Figuras}

1 Determinantes do Desenvolvimento da criança . . . . . . . . . . . . . 22

2 Distribuição dos anos de atraso escolar . . . . . . . . . . . . . . . 57

3 Proporção dos homens em relação as categorias de anos de atraso escolar . 58

4 Proporção dos negros em relação as categorias de anos de atraso escolar . . 58

5 Proporção de indivíduos que moram na área urbana em relação as categorias de anos de atraso escolar . . . . . . . . . . . . . . . . . . . 59

6 Comparação entre as distribuição binomial negativa, poisson e dos dados . 72 


\section{Introdução}

O estudo dos determinantes do sucesso econômico representado por níveis de produtividade, de salários e de desempenho escolar, tem atraído a atenção de cientistas sociais desde do final do século XIX. Esses estudos buscam identificar e mensurar os fatores responsáveis por melhores esses melhores resultados.

Entre os economistas em particular, o assunto ganhou grande destaque com o trabalho de Gary Becker, que formalizou a importância da decisão familiar na formação e acúmulo de capital humano. Seguindo a tradição de Becker, o sucesso dos jovens depende de de-

cisões tomadas pelos pais acerca da formação do capital humano na família. É justamente o estudo do processo de acúmulo de capital humano que ocupa um lugar central na agenda de pesquisa dos determinantes do crescimento e desenvolvimento econômico. Tal como evidenciado por Mankiw, Romer e Weil (1992) a formação do capital humano é um dos principais fatores para explicar as diferenças observadas com relação ao crescimento dos países. Hanushek (1992) corrobora essa informação ao provar que apenas a educação com qualidade é responsável por elevar o crescimento econômico. O nível de produtividade de um país está, portanto, limitado pelas habilidades adquiridas pela população.

Para ilustrar essa situação, um exemplo foi retirado da revista exame. Essa reportagem descreve o relato do RH da empresa(LG) que compara os níveis de produtividade das empresas localizadas no Brasil e na Coréia(sede). As duas unidades contam com o mesmo número de funcionários, teoricamente dotado com o mesmo nível de formação escolar, o ensino médio completo. As linhas de produção da LG em Taubaté, no interior de São Paulo, montam nove celulares por hora. Enquanto as linhas da fábrica da cidade de Pulsan, no interior coreano, produzem 15 aparelhos por hora - quase $70 \%$ a mais. A diferença é que os operários coreanos foram educados por um dos melhores sistemas de 
ensino público do mundo, e o brasileiro, por um dos piores. "O poder de concentração, a capacidade de aprendizagem e a agilidade mental dos coreanos são impressionantes. Os brasileiros ainda tentam e se empenham, contudo, precisam de mais treinamento, mais orientação e são mais dispersos".

A variável produtividade dos indivíduos, relatada no exemplo, representa uma medida observada que indica níveis de acúmulo de capital humano. Nesse caso, o nível de escolaridade não foi capaz de diferenciar os trabalhadores mais habilidosos, ou aqueles que representam maior acúmulo de capital humano. Na literatura contemporânea, esse resultado é estudado, pois o nível de escolaridade não é mais um fator singular que diferencia as qualidades entre os indivíduos (HANUSHEK, 2001).

Como visto anteriormente, a produtividade é uma variável que representa a diferença em nível de capital humano acumulado entre os indivíduos. Existem, entretanto outras variáveis que afetam o nível de acúmulo de capital humano. Outra variável que tem esse papel de representar as habilidades dos indivíduos é o desempenho escolar.

O desempenho escolar pode ser medido de diversas formas, por exemplo, a partir de testes de conhecimento específicos em matérias chaves(Português e Matemática) como feito no SAEB. Ou ainda de forma indireta pela defasagem-idade série. As pesquisas na área da educação provam a existência da correlação inversa entre o atraso escolar e a formação de habilidades nas crianças de mesma idade (MEISELS; LIAW, 1993; BYRNES; YAMAMOTO, 1989). Os registros do SAEB de 2003 mostram que alunos com defasagem idade-série apresentavam menores resultados nos testes de proficiência. Ainda que, não seja possível determinar a direção de causalidade entre defasagem e proficiência estes dados deixam claro que existe forte correlação entre elas. Dessa maneira, é razoável utilizar o atraso escolar como o indicativo de desempenho escolar.

A defasagem idade série no Brasil é considerada um dos principais problemas do sistema educacional do país, pois além de representar falhas na formação das habilidades do indivíduo, para a sociedade e para o Estado, é um fenômeno gerador de enorme desperdício de recursos.

No período entre 7 e 17 anos é a fase de desenvolvimento fundamental escolar, é 
nessa fase que o atraso escolar pode ser adquirido e, em geral, as crianças ainda estão sob tutela dos pais. Cameron e Heckman (1998) concluíram que entre os 16 e 18 anos os indivíduos já constituíram a maior parte de sua capacidade cognitiva. Nesse período as características familiares influenciam diretamente o atraso escolar, uma medida indicativa de capital humano acumulado.

Por essa ótica, Horowitz e Souza (2005) estudaram a influência da estrutura familiar no atraso escolar. A distribuição do atraso escolar é a proxy utilizada para a dispersão do capital humano, pois diferencia as crianças quanto à qualidade das habilidades adquiridas. Mesmo que a medida de capital humano acumulado seja algo complexo e não observável, pois é resultado de um processo de construção durante toda a vida, as falhas desse processo permitem qualificar a diferença de performance do capital humano acumulado. Durante o período escolar, as crianças estão sob o cuidado dos pais, esse fato intensifica a importância das características familiares no atraso escolar.

Assumindo que a criança deve ingressar na escola aos sete anos de idade, define-se o atraso escolar como a diferença entre a série que a criança está cursando ou que tem concluída e a série que deveria pertencer sem nenhuma reprovação. O atraso pode ser causado por três situações: abandono escolar, repetência e atraso na matrícula. Estar fora da idade ideal acarreta sérios prejuízos ao indivíduo, que em geral comprometem a qualidade de aprendizagem, criam graves conseqüências de auto-estima e problemas na própria trajetória escolar.

O atraso escolar no cenário brasileiro não está apenas relacionado à falta de vagas oferecidas. O baixo crescimento demográfico e a expansão do número de vagas incentivada pelo Fundef foram responsáveis por elevar a proporção entre as crianças efetivamente matriculadas e aquelas que estão em idade escolar. A evasão escolar, antes justificada pela necessidade da criança ajudar na composição da renda familiar, também foi reduzida devido aos auxílios governamentais tais como programas bolsa familia. Desta forma, as crianças com atraso escolar são aquelas com dificuldades de aprendizagem, com falhas no processo de formação das suas habilidades e baixo nível de capital humano acumulado.

Neste contexto o estudo dos determinantes do atraso escolar é bastante pertinente 
para a agenda de desenvolvimento do Brasil. Este trabalho apresenta um contribuição nesse sentido utilizando os modelos de contagem e dados da PNAD de 1996. A variável analisada "atraso escolar" é uma variável discreta e não negativa, caracterizada como dados em contagem. A PNAD 96 foi escolhida por fornecer dados sobre a escolaridades dos pais dos pais e por não representar nenhuma política de melhoria direcionada para a redução do atraso escolar. 


\section{Atraso escolar e educação no Brasil}

No início da década de 1990, os baixos níveis médios de escolaridade da população adulta que oscilavam em torno de 5 anos, motivaram as mudanças das diretrizes básicas do ensino. As mudanças ocorreram em vários sentidos, em novas normas institucionais e nas formas de financiamento. O objetivo dessa mudança era melhorar primeiro o acesso a escola, considerada condição mínima, conjuntamente com o aumento da qualidade do ensino das crianças.

Para melhoria no acesso, uma nova forma de financiamento de ensino, definida Fundo de Manutenção e Desenvolvimento da Educação Fundamental (Fundef), foi criada. Nele, os recursos da educação são repassados diretamente aos municípios de acordo com a quantidade de alunos matriculados em suas escolas. Essa medida foi responsável por aumentar a freqüência de matrículas das crianças e adolescentes para $97 \%$ entre as crianças de 7 a 14 anos. Esse primeiro passo foi importante para garantir o acesso à educação a todas as crianças em idade escolar.

Aliado a esse recurso normativo, outro fator que garantiu a possibilidade de melhoria no acesso à escola foi a redução do crescimento demográfico para 2,5\% em média ao ano ${ }^{1}$. Nesse sentido, destaca-se que o Brasil atravessa, atualmente, um período demográfico favorável (que alguns autores denomina como "a fase de ouro da transição demográfica") em que os benefícios da estabilização e eventual decréscimo das coortes de idade mais jovens ainda não são anulados pelo rápido crescimento da população idosa.

Em 1980, o tamanho da população entre 7 e 14 anos era de pouco menos de 23 milhões

\footnotetext{
${ }^{1}$ Dados do IBGE de 2003
} 
de crianças, em 1993/94 esses números atingiram um pico de 27,5 milhões, declinando nos anos seguintes para atingir um nível pouco acima de 26 milhões em 2000. Assim, podemos verificar que essa faixa de idade diminuiu em termos absolutos em quase 1,5 milhão nos últimos seis anos. A prova da fase de ouro da transição demográfica é a redução da freqüência relativa dessa coorte de sete a quatorze anos de idade de 19,2\% da população total em 1980 para 15,7\% em 2000. Mais importante ainda é a razão de dependência em relação à população adulta (de 15 a 64 anos de idade). Em 1980 essa relação era de uma criança para cada três adultos, em 2000 era mais de quatro adultos para cada criança em idade escolar obrigatória. Obviamente, isto representa um fator de atenuação da demanda agregada por educação básica e de melhores condições da sociedade em arcar com os custos do sistema educacional.

Outro fator que incentivou o aumento da freqüência foi a redução da evasão escolar a partir dos auxílios governamentais como o Bolsa-Família. Esse programa visa manter a criança carente na escola a partir de auxílios à renda familiar. Essa renda complementar pode garantir que a criança em idade escolar não precise trabalhar.

O histórico dos fatos mostrou que em geral, o atraso escolar na década de 90 não decorre de dificuldade de acesso ou de evasão escolar. Assume-se que em geral, os alunos com atraso escolar são aqueles que apresentam uma falha na qualidade da habilidade. Por esse fato, a variável "atraso escolar" será utilizada como indicativo de desempenho escolar nesse estudo.

A partir dos dados do $\mathrm{SAEB}^{2}$ de 2003, pode-se identificar que o panorama da freqüência do atraso escolar apresenta uma correlação negativa entre as regiões mais desenvolvidas e o atraso escolar. As regiões Sul e Sudeste, caracterizadas como as mais desenvolvidas, apresentaram a proporção das crianças sem atraso escolar em torno $25 \%$ e $32 \%$, respectivamente. O pior índice foi apresentado pela região Nordeste que mantém 58\% das crianças nessa situação de atraso escolar.

A comparação do desempenho escolar entre as regiões apresentou a mesma carac-

\footnotetext{
º́rgão responsável pela avaliação do SAEB é o Instituto Nacional de Estudos e Pesquisas Educacionais Anísio Teixeira (Inep/MEC)
} 
terística de correlação acima, regiões consideradas mais pobres apresentam piores níveis de desempenhos. No Nordeste, $75 \%$ das crianças da $4^{\text {a }}$ série estão classificadas nos níveis crítico e muito crítico em leitura. No Sul e Sudeste essa proporção cai para $47 \%$ e 44\%, respectivamente. A mesma situação é verificada na prova de matemática, a freqüência das crianças nas últimas categorias no Nordeste, no Sul e no Sudeste são respectivamente 69\%, 41\% e 39\%. Ainda que não seja possível determinar a direção de causalidade entre defasagem e proficiência estes dados deixam claro que existe forte correlação entre elas. Foi visto que existe uma correlação entre as regiões com maior desempenho, as regiões com mais recursos e menor atraso escolar.

Os dados apresentados também evidenciaram uma grande heterogeneidade do nível de escolaridade entre a população brasileira. Os dados permitiram comprovar que além da grande diferença de performance dos alunos entre as regiões, a freqüência das crianças com baixo desempenho e atraso escolar ainda é elevada em níveis gerais.

Outros resultados, apresentados pelo SAEB, provam que a qualidade do ensino oferecido ainda é baixa. Essa última avaliação mostra que 55\% das crianças que freqüentavam a $4^{\mathrm{a}}$ série do ensino fundamental, em 2003, têm uma competência de leitura abaixo do nível considerado apropriado à série. Elas apresentam graves dificuldades em ler textos simples, curtos, escritos na ordem direta e de encontrar em tais textos as informações explícitas. Em Matemática, $52 \%$ das crianças brasileiras da $4^{a}$ série não consolidaram plenamente os algoritmos da soma, da subtração, da multiplicação e da divisão. A média de proficiência obtida pelas crianças de $4^{\mathrm{a}}$ série é baixa. A pontuação 200 indica que o indivíduo apresenta nível mínimo satisfatório em leitura, mas a pontuação média dos alunos foi de 169 pontos e em matemática de 177 pontos.

Os dados nacionais apresentados retrataram o baixo desempenho educacional, esse resultado foi agravado por evidências de heteregeneidade entre as regiões. O desempenho educacional brasileiro apresentado em outros estudos comparativos com relação aos países de níveis semelhantes de desenvolvimento e renda per capita destacam ainda mais o atraso de sistema educacional brasileiro.

O relatório PISA 2000 avalia entre países, o nível de capacidade de leitura da criança, 
ao diferenciar entre os que ultrapassam os limites da decifração lingüística, daqueles que atingem um campo semiótico amplo do ensino disciplinar da língua. Nessas provas de desempenho foram comparadas as diferenças entre as qualidades das habilidade dos indivíduos.

Como parâmetro de comparação os países mais avançados economicamente atingem o nível 3 (481-552) tendo como melhor colocado nessa categoria a Finlândia (546) e pior dessa a Alemanha (483). Nessa categoria os alunos possuem habilidades de leitura que permitem localizar e interpretar as informações de forma a relacionar os assuntos. Enquanto, o Brasil (396) encontra-se no nível 1 (335-407). Nesse nível, o indivíduo é capaz a partir da leitura de localizar apenas informações que estejam colocadas de forma explícita. O México que apresenta indicadores de renda per capita $U S \$ 8.296$, índice de desenvolvimento humano (IDH) em 0,784 e coeficiente de Gini 53, 7, semelhante ao Brasil que possui respectivamente $U S \$ 7037 ; 0,747$ e 60,0, obteve melhor desempenho(422).

Esses resultados mostram que o nível qualitativo educacional brasileiro é considerado baixo, mesmo quando comparado aos outros países com o grau de desenvolvimento sócioeconômico semelhante.

A educação é um dos principais insumos para o desenvolvimento sustentável do país (BARRO; LEE, 2001). Os dados da educação brasileira apresentados mostram que ainda estamos muito aquém da qualidade necessária para atingir patamares de desenvolvimento sustentável e de longo prazo. 


\section{Revisão da literatura}

Becker e Tomes $(1986,1979)$ foram os pioneiros na modelagem do comportamento familiar no processo de formação do indivíduo. Esses autores, acreditam que a formação das habilidades nas criança é determinada tanto pelas heranças genéticas intrínsecas quanto pelas decisões de investimento em capital humano feito pelos pais.

O nível de herança genética depende do grau de transmissão classificadas entre zero e um, descrita por um processo de Markov. Na média, pais que têm o nível de escolaridade acima da média terão crianças com altos níveis de escolaridade, mas não tão altos ao compará-los ao nível médio de seus pais. Os pais são os responsáveis por transmitir heranças culturais e padrões de comportamento tais como maior comprometimento nos estudos, hábitos de leitura, contato com música e artes.

Esses estudos mostram que a qualidade da habilidade do indivíduo é um reflexo do acúmulo de capital humano ao longo da vida. Essa "herança", capital humano acumulado irá refletir nos índices de produtividade e desempenho escolar.

Os pais preocupam-se com o desenvolvimento das capacidades da criança com a intenção de prepará-los para que possam atingir melhor sucesso econômico. Por isso, se preocupam em investir nos processos que ajudam o indivíduo no acúmulo de capital humano. Os principais investimentos em capital humano feitos pelos pais são o acesso a educação de qualidade, cuidados com a saúde e higiene, incentivo às atividades que desenvolvam as capacidades e habilidades que auxiliem na educação formal entre outros (BECKER; TOMES, 1986).

Os estudos de Gary Becker em capital humano criaram novas linhas de pesquisa ligadas à abordagem da teoria de comportamento familiar. A unidade de produção é a 
família, que emprega recursos para transformá-los em capital humano com o objetivo maior de elevar os níveis de utilidade a todos os seus membros. Os pais são responsáveis por grande parcela dos recursos na unidade familiar, que são obtidos por meio de rendimentos e venda de trabalho. O papel dos pais na família é a captação e alocação de recursos, de forma a maximizar os níveis de utilidade de seus membros.

O nível de educação dos pais pode afetar a formação de capital humano do filho em dois sentidos: diretamente no acompanhamento da formação educacional do filho e indiretamente no fornecimento de recursos financeiros. Pais mais hábeis são aqueles com capital humano elevado que garantem melhor formação de capital humano no filho.

As escolhas tomadas pelos pais a partir de suas próprias características e condições interferem de forma direta e indireta na formação do filho. O desenvolvimento da criança não é um processo linear simples e direto, por isso, cada um compõe uma combinação diferente de acúmulo de capital humano.

Entender e compreender o processo, os agentes e o resultado do investimento em capital humano na prática é importante para a formação de teorias. Esses autores ajudariam a compor novos cenários que direcionariam melhor os futuros investimentos. O maior nível de capital humano acumulado significa pessoas melhor qualificadas, condição básica para que o país atinja o desenvolvimento sustentável.

\subsection{Modelos Teóricos}

Mensurar o impacto das variáveis responsáveis pela falha ou pelo sucesso na formação do indivíduo permite identificar a relevância de cada uma delas nesse processo. Entretanto, devido à natureza endógena das variáveis do processo de desenvolvimento, estruturar modelos de forma completa torna-se uma tarefa árdua.

Como visto na figura (??), os efeitos de causalidade de cada ação são compostos e interdependentes. Leibowitz (1974) apresentou um modelo geral do processo de desenvolvimento do indivíduo no qual o objetivo era testar a transmissão das qualidades intrínsecas dos pais para os filhos. O modelo buscou comprovar graus de hereditariedade que mesmo 


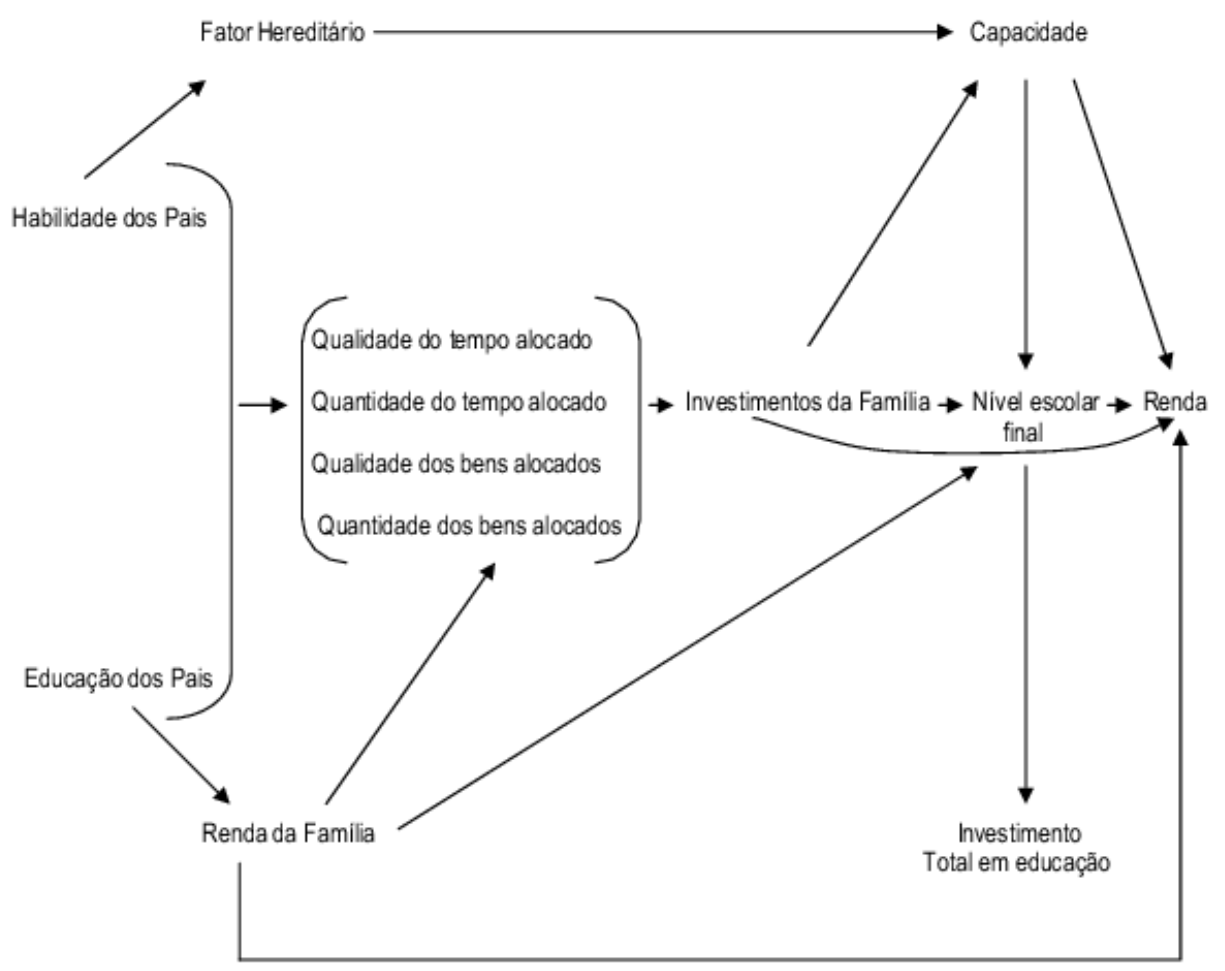

Figura 1: Determinantes do Desenvolvimento da criança

não observadas diretamente manifestavam-se ao longo de diversas variáveis. No modelo, a educação dos pais é responsável por influenciar a renda familiar, os investimentos alocados dentro da família, o nível escolar da criança e também a renda futura dela. A habilidade intrínseca dos pais é a variável chave no ato da tomada de decisão da alocação de recursos, por isso o papel dos pais é fundamental no processo de desenvolvimento da criança. A analogia é feita pelo sistema recursivo, da seguinte forma:

- Capacidade da criança $=f_{1}$ (fatores genéticos, investimento familiar)

- Educação da criança $=f_{2}$ (capacidade da criança, investimento e renda familiar)

- Renda da criança $=f_{3}$ (investimento e renda familiar, educação da criança, investimento em treinamento, capacidade da criança)

A variável capacidade da criança depende dos fatores genéticos e das condições familiares. A educação da criança, por sua vez, depende da capacidade da criança e do investimento e renda familiar. A renda futura da criança depende dessas variáveis de- 
scritas somadas às variáveis de investimentos e de renda familiar que também já foram incluídas nas outras variáveis.

Becker e Tomes (1979) e Leibowitz (1974) assumem em seus modelos a mesma função utilidade para todas as decisões feitas dentro do domicílio. Esse pressuposto é criticado por aqueles que acreditam que a decisão familiar seja um modelo composto pelas funções de utilidades individuais como em um modelo de barganha aplicado dentro da própria família. McElroy (1990) formulou um modelo de barganha tipo Nash-Stackelberg para o processo de decisão familiar. A maioria dos resultados e das análises mais recentes sugere um comportamento mais consistente aos modelos de escolha com preferências individuais (BEHRMAN; POLLAK; TAUBMAN, 1995; BEHRMAN; TAUBMAN, 1990). Uma alternativa para modelar essa situação é construir um modelo com múltiplos estágios.

No modelo de múltiplos estágios, com funções utilidade para cada individuo, o agente segue restrições de oportunidades e limitações segundo as condições de recursos dos pais. Essas funções utilidade estão de acordo com as decisões tomadas pelos pais tais como: tamanho da família e sua estrutura, renda e alocação do tempo, que afetam o desenvolvimento da criança. E apenas no último estágio, as crianças maximizam a função utilidade dado o investimento em capital humano.

Mesmo de forma incompleta, essas análises simples e diretas podem contribuir no planejamento de políticas públicas ao apresentar o impacto das características familiares no processo de formação das habilidades das crianças.

\subsubsection{Modelo sem transferência}

A seguir, o modelo simplificado com apenas uma criança de Ermisch e Francesconi (2001) será apresentado para mostrar a influência das características familiares no processo de formação da criança.

Nesse modelo, assume-se que renda futura da criança e do adulto são bens da família. A renda futura da criança é representada por e e a renda dos pais por $r b$, em que $b$ é a quantidade de transferências (doação e heranças) e $r$ é a taxa de juros do mercado. A remuneração futura da criança é determinada principalmente pela característica intrínseca 
de cada criança $(\epsilon)$ e pela formação escolar.

O processo de desenvolvimento é contínuo e dependente do resultado dos períodos anteriores. Quanto maior o desenvolvimento no período anterior $(t-1)$, menores são as chances de lacunas e falhas na formação nos períodos subseqüentes $(t)$. Devido à natureza acumulativa do processo, a quantidade e a qualidade dos investimentos realizados pelos pais durante a infância são considerados fundamentais.

As bases da formação escolar e das características intrínsecas individuais são consolidadas no período em que a criança está sob cuidados dos pais. Outro fator que intensifica o papel dos pais durante esse período é a natureza dependente da criança que ainda está em processo de formação. Os pais são responsáveis por promover as condições de recursos e tomadas de decisão sobre o investimento em capital humano na criança. Por esse fato, as características familiares são determinantes importantes para a formação da criança.

Durante a adolescência, o indivíduo ainda vive de acordo com as condições de vida provida pelos pais. Entretanto, ele já participa das escolhas do nível de aproveitamento de capital humano acumulado. As escolhas da criança são feitas de acordo principalmente com os valores construídos durante a infância. No modelo, a dinâmica das decisões de investimento é estática e segue a lógica das escolhas direta dos pais na educação de seus filhos.

A função de remuneração das crianças é dada por: $e=f(S, \epsilon)$, em que $S$ é o nível educacional atingido pela criança (resultado do investimento em capital humano) e $\epsilon$ representam as características intrínsecas da criança.

A função de preferências dos pais é representada por uma função utilidade $U(x, e+r b)$, em que $x$ denota o consumo próprio. Os pais decidem alocar os recursos entre $x$ (consumir), $b$ (transferências) e $S$ (investir em capital humano no filho), de forma a maximizar a função utilidade sujeita à restrição $y=x+b+p_{S} S$, em que $p_{S}$ é o custo da educação e $y$ é a renda familiar. Como resultado desse problema de otimização, encontramos que o nível de educação escolhido pelos pais deve satisfazer a seguinte condição:

$$
p_{S} \leq[\partial f(S, \varepsilon) / \partial S] / r
$$


O lado direito da equação (3.1) representa o retorno marginal do investimento em educação e o lado esquerdo os custos da educação. Este resultado mostra que os custos em investimento em educação realizados pelos pais superam o retorno marginal salarial obtido pela criança. Ou seja, os pais apenas fazem investimento em capital humano se acreditam que cada ano a mais de estudo será no futuro recompensado com melhores salários.

Esse modelo ilustra como o recurso familiar é alocado na educação da criança. A renda é um fator limitante nesse modelo, em que o pai tem que escolher como distribuir sua renda entre as possíveis opções. Pais com renda mais elevada têm acesso ao capital próprio para a formação de capital humano de seu filho, o que eleva as chances de um melhor desenvolvimento da criança.

\subsubsection{Modelo com transferência}

Anteriormente, verificamos que a relação dos pais na decisão de investimento na educação do filho depende dos recursos disponíveis. Nessa seção, serão apresentados modelos em que o filho não depende diretamente da renda do pai e da mãe, mas de transferências $b$ que dependem diretamente da renda.

Caso os pais façam transferências monetárias para seu filho (isto é $b>0$ ), a equação (3.1) torna-se uma igualdade. Note que, nesse caso o nível educacional das crianças não dependerá mais da renda dos pais, apenas da taxa de juros, dos custos da educação e dos ganhos em produtividade dado pelas características instrínsecas dos indivíduos. Dado $e=S^{\gamma} \epsilon \operatorname{com} 0<\gamma<1$, então o nível de educação ótimo é:

$$
S^{*}=\left(\gamma \epsilon / r p_{S}\right)^{1 /(1-\gamma)}
$$

Mesmo que a renda dos pais não influencie diretamente no investimento em educação, a quantia monetária de transferências depende diretamente da renda dos pais. Ou seja, a renda dos pais continua como um dos limitantes do investimento na educação da criança.

Esse modelo segue a função de utilidade representada por: 
$U=\alpha \ln (x)+(1-\alpha) \ln (e+r b)$. E a função da transferência ótima segue

$$
b^{*}=(1-\alpha)\left[y-p_{S} S^{*}\right]-\alpha e^{*} / r,
$$

em que $e^{*}=S^{* \gamma} \epsilon$ é a renda ótima futura da criança e $S^{*}$ é o investimento ótimo na educação do filho, representado na equação (3.2). Os pais fazem de forma eficiente as transferências monetárias para seus filhos, de acordo com a sua renda e suas preferências.

O nível educacional da mãe e do pai influencia a parcela de investimento em capital humano no filho. $S_{m}$ representa a parcela do investimento em capital humano relacionada à educação da mãe e $S_{f}$ é a parcela do investimento influenciado pelo nível educacional do pai.

As variáveis $S_{m}, S_{f}$ e $\epsilon$ estão correlacionadas de forma positiva, e representam a influência das heranças genéticas e dos hábitos diversos dos pais na formação das características intrínsecas das crianças $(\epsilon)$. Pais com o nível educacional elevado podem promover melhor ambiente para o acúmulo de capital humano em seus filhos, pois estão melhores preparados para incentivar e estimular adequadamente o desenvolvimento de habilidades na criança.

Nesse caso, a educação dos pais é um indicador de melhores investimentos na educação da criança. Pais mais educados possibilitam melhores condições de recursos para a criança por fornecer melhor renda e melhor investimento em capital humano. Mesmo que a renda não influencie o modelo, ela está relacionada com o nível de transferência que é responsável pelo nível de investimento em educação da criança.

Caso os níveis educacionais dos pais não sejam semelhantes, o custo educacional $p_{S}$ da criança é determinado pela quantidade de investimento realizado na educação pelos pais. Por exemplo, como no modelo restrito de investimento em capital humano na criança composto por insumo tempo de dedicação e produção. O insumo "tempo de dedicação" é representado por $t_{j}$, em que $j$ indica o responsável, sendo $m$ a mãe e $f$ o pai. E $h_{j}$ é a produção de capital humano de responsabilidade do parente $j$, segue então o modelo:

$$
S=h_{f} t_{f}+h_{m} t_{m}
$$


Seja o valor do salário da mãe $w_{m}$ e o custo do capital humano do filho $p_{S}=w_{m} / h_{m}$. Então, a mãe apresenta uma vantagem comparativa quando proporciona maior acúmulo de capital humano em relação aos outros responsáveis, ou seja, $w_{m} / h_{m}<w_{f} / h_{f}$. Como a habilidade da mãe está correlacionada tanto com o nível salarial $\left(w_{m}\right)$ quanto com a produtividade de capital humano no domicílio $\left(h_{m}\right)$, a vantagem comparativa existe quando a produção de capital humano supera o salário obtido no mercado.

Outra situação possível ocorre quando o pai não contribui na formação de capital humano do filho, ou seja, no modelo restrito em que não existe $h_{f}$, na equação (3.4). Este fato eleva os custos de acúmulo de capital humano $\left(p_{S}\right)$ pois a parte do investimento em capital humano do filho relacionada ao pai $S_{f}$ simplesmente não existe, e a correlação entre $\epsilon$ e $S_{f}$ também não.

Os resultados consideram o insumo "tempo de dedicação" dos pais como sendo substitutos imperfeitos. Nesse modelo, dado que o custo de produção de capital humano do pai seja menor, o efeito da educação do pai, mesmo que importante, é menor que a educação da mãe.

As situações descritas acima mostram que o efeito causal da educação dos pais não é linear no processo de desenvolvimento do filho. Entretanto, esse efeito influencia de forma indireta e relativa ao investimento no capital humano do filho por meio das outras variáveis comportamentais.

\subsubsection{Transferências monetárias de pais pobres}

Os pais pobres que não têm condições para fazer transferências monetárias, realizarão investimento privado abaixo do ponto em que retorno marginal é igual ao custo marginal da educação. Em outras palavras, os pais pobres investem menos que a quantidade de equilíbrio ótima. Em contrapartida, os pais ricos fazem as transferências e o investimento ótimo em capital humano correspondente a sua renda. A função a seguir representa o investimento ótimo em capital humano:

$$
S^{*}=\gamma(1-\alpha) y /[\gamma(1-\alpha)+\alpha] p_{S}
$$


E o impacto da educação da mãe $\left(S^{m}\right)$ na formação de capital humano no seu filho é:

$$
\partial S^{*} / \partial S_{m}=\left(\partial y / \partial S_{m}\right)\left(\partial S^{*} / \partial y\right)=\left(S^{*} / p_{S}\right)\left(\partial p_{S} / \partial S_{m}\right)
$$

A equação (3.5) indica que as características intrínsecas das crianças não são resultados dos investimento em capital humano feito pelos pais $\left(S_{m}\right.$ e $\left.S_{f}\right)$. Desta forma, as habilidades dos pais que seriam responsáveis pela formação do capital humano não são relevantes nessa situação. Assim, mesmo pais com baixa escolaridade podem ter filhos com investimento ótimo em capital humano. As características intrínsecas dos pais deveriam estar representadas pois poderiam ser responsáveis por resultados de diminuição ou acréscimo de investimento de capital humano, principalmente quando os pais são pobres e não fazem transferências monetárias (BECKER; TOMES, 1986).

Os efeitos da educação da mãe no que tange os investimento em capital humano $\left(S_{m}\right)$ são diferenciados dos efeitos da renda familiar. Nesse caso, a educação da mãe não afeta o custo de investimento em capital humano do filho mas afeta indiretamente a renda familiar. O impacto da educação do pai $\left(S_{f}\right)$ é análogo a (3.6), mas o efeito substituição $\left(\partial p_{S} / \partial S_{f}\right)$ pode ser nulo se a parcela de envolvimento do pai na formação de capital humano $\left(S_{f}\right)$ for baixa.

Caso os pais não façam transferências, a correlação entre a educação dos pais e dos filhos pode ser representada como um efeito causal da educação dos pais. Isso porque o investimento em capital humano não atingiu o ponto de equilíbrio entre o retorno marginal e o custo marginal desse investimento. Nesse caso, as preferências e os recursos em relação aos custos marginais e as habilidades dos pais determinam o nível de educação escolhida para filho.

O modelo estático é diferente do modelo dinâmico (LOURY, 1981). A análise dinâmica feita por Maoz e Moav (1999) mostra a correlação entre a educação dos pais e dos filhos crescente e de forma mais acelerada de acordo com a educação dos pais pois, pais mais educados têm acesso a mais recursos, não apenas resultado da correlação entre a capacidade intensificada entre gerações.

O modelo de transferência de ganhos separados gera os mesmos resultados do modelo 
dos pais pobres que não fazem transferências (BEHRMAN J. R.; WOLFE; BLAU, 1981). Nesse modelo, as preferências dos pais são separadas do consumo e das transferências financeiras para os filhos. Novamente, o recurso e as preferências dos pais determinam o nível educacional do filho, não apenas o custo marginal e as características intrínsecas das crianças.

Os pais contribuem para a manutenção da posição sócio-econômica do filho ao disponibilizar recursos que garantam o maior acúmulo de capital humano ao longo do desenvolvimento dele.

\subsection{Modelos Empíricos}

Coleman (1988) definiu uma nova forma de capital necessário para a concretização de outras formas de investimentos, o capital social. O capital social pode ser definido como o valor associado às relações entre os agentes da sociedade. Essas relações tornar efetivos os investimento em capital humano responsáveis por desenvolver as habilidades nos indivíduos.

Por essa ótica, o papel da família torna-se ainda mais importante, pois além de financiador direto de investimento de capital humano e físico, ela é responsável por efetivar as diversas formas de investimento. As diferenças entre as qualificações dos indivíduos resultam da interação entre as diferentes formas de investimento de capital: físico, humano e social, que estão altamente relacionadas às características familiares.

Outras abordagens como os estudos de mobilidade social também destacam o papel da família ao avaliar que as características dos pais são responsáveis por condições futuras dos filhos. Esses estudos iniciaram por volta de 1920 nas ciências sociais com intuito de verificar de forma empírica os determinantes do sucesso econômico. Esses pesquisadores, ao mensurar a mobilidade social, encontravam o impacto entre as ocupações dos pais e dos filhos. Outra questão analisada nessa área é a possibilidade de mensurar qual parte dos ganhos dos filhos é determinada pela situação dos pais. A existência da correlação entre os ganhos dos pais e dos filhos significa uma sociedade com pouca mobilidade social. 
O primeiro modelo causal desse processo foi feito por Duncan e Hodge (1963). Esses autores criaram o índice de prestígio ocupacional a partir da descrição do ciclo de vida sócio-econômico entre as três esferas: família, escola e trabalho (DUNCAN, 1961). Para isso, foi criado um sistema de equações recursivas que utilizou uma adaptação dos dados contidos no suplemento de uma pesquisa da população americana realizada em 1962. A estimação descreveu a relação entre as características familiares e o desenvolvimento da criança ao longo do tempo. A partir disso, foi feita a avaliação dos efeitos dessas variáveis na determinação do sucesso do status socioeconômico. Constatou-se que a formação do status ocupacional sofre impactos da escolaridade e das características familiares. Entretanto, a variável escolaridade também é determinada pelas características familiares, o que cria uma superestimação dos coeficientes dessas variáveis quando são tratadas como variáveis exógenas.

Um estudo mais avançado nesse mesmo contexto foi realizado por Cameron e Heckman (1998). Eles examinaram a influência das famílias na probabilidade de transição para um nível social superior. Entretanto, cada estrutura familiar tem condições diferentes e suas probabilidades de mudança de camada social também são distribuídas de forma particular.

Assim, foram criadas funções distribuições para alguns padrões de estruturas familiares, descartando-se a distribuição uniforme. Nesse caso, os autores utilizaram ferramentas estatísticas para adequar as probabilidades para cada tipo de família a partir do conhecimento desse comportamento. Após essas adequações, o resultado mostrou que a renda não é um fator determinante para o progresso nos estudos (ingresso na faculdade). Como não existe uma restrição de renda (determinada pelos pais) no processo de desenvolvimento da criança, esse estudo mostra que existem possibilidades de transição de nível social.

Hauser e Featherman (1977) e Hauser e Sewell (1986) agregaram à estrutura de desenvolvimento do padrão do ciclo de vida ocupacional os conceitos de capital humano. Esses autores focaram a relação entre a decisão por acréscimos nos anos de estudos e as características familiares nos determinantes dos salários, mesmo que essa relação seja endógena. 
A partir da introdução dessas novas definições e dos dados de 1973, foi possível estimar o mesmo modelo de Duncan e Hodge (1963) para que pudessem ser feitas comparações entre o comportamento padrão da mobilidade entre gerações da década de 60 e 70 . Os resultados mostraram que o impacto das características familiares realmente era superestimado devido à relação endógena entre a escolaridade e as características familiares tratadas de forma exógena no primeiro estudo.

Existe considerável evidência empírica de que os investimentos em capital humano nos primeiros anos de vida das crianças são determinantes fundamentais dos resultados atingidos ao longo da vida. Esse resultado reforça a importância dos pais no processo de formação do indivíduo, pois nos primeiros anos de vida das crianças, além de não terem autonomia plena de seus atos, em geral, estão sobre custódia dos pais.

Os pais responsáveis por investimentos em capital humano das crianças nesses primeiros anos são fundamentais no resultado do processo de desenvolvimento da criança (CUNHA et al., 2005). Desta forma, a criança que recebeu desde os primeiros anos de vida recursos, estímulos e cuidados adequados para o seu desenvolvimento obteve como resultado melhor formação do lado cognitivo, maior acúmulo de capital humano.

O lado cognitivo é responsável pela formação de raciocínio lógico, pela autonomia e por outras formas de associação que ajudam no processo de formação da aprendizagem de assuntos não cognitivos ou parte formal da educação. Assim, a partir do conhecimento que a educação é um processo de construção, a formação do lado cognitivo nos primeiros anos de vida é bastante importante no desenvolvimento do indivíduo.

Dado o conhecimento desse processo de formação do conhecimento, Cunha et al. (2005) propõem uma nova estrutura teórica, ao introduzir dois novos conceitos: a autonomia produtiva (self-produtivity) e a complementariedade (complementarity) dos investimentos em capital humano. Para esses autores, o investimento nas fases iniciais do ciclo de vida desenvolve a autonomia produtiva e permite que ela seja responsável pelo efeito de complementariedade dos investimentos futuros em capital humano. Quanto mais antecipados os estímulos e os investimentos, maior será o nível da autonomia do aprendizado da criança, ou seja, terá maior acúmulo de capital humano para construir e desenvolver 
novos conceitos.

Para as crianças com bom nível de desenvolvimento da autonomia de aprendizado, os novos investimentos em capital humano serão formados com maior eficiência com menores custos, devido ao caráter construtivo da formação. Esse efeito traz "facilidade" do aprendizado a partir do desenvolvimento do lado cognitivo, que diminui o custo de oportunidade em continuar os estudos. Assim, como descrito acima, o desenvolvimento do lado cognitivo é responsável pela formação dos efeitos autonomia do aprendizado e complementariedade.

Os estudos empíricos estão sujeitos às restrições de dados, às limitações de métodos econométricos entre outros. A partir da descrição de alguns dos principais estudos foi possível notar que essas análises utilizavam forma reduzida e ou simplificada devido a tais restrições.

Nos modelos empíricos a principal variável independente eram as características familiares representadas por escolaridade, experiência, renda, ocupação dos pais entre outras. E o processo de desenvolvimento do indivíduo, a variável dependente, era representada por variáveis como a escolaridade da criança, desempenho da criança, estrutura familiar, salários entre outros. Em geral, as variáveis explicativas desse modelo são endógenas, portanto, estimativas clássicas geram estimativas viesadas. Por isso, o grau de confiança dos estudos empíricos depende do conhecimento das razões da endogeneidade e a técnica adequada para solucionar essas questões.

É importante esclarecer que os resultados encontrados sobre o processo de desenvolvimento da criança apresentam diversas conclusões quanto à mensuração dos determinantes, portanto não devem ser utilizados estudos diferentes para comparação direta de resultados. Outra questão relevante é que as únicas variáveis que sempre afetam de forma positiva o desenvolvimento do indivíduo são as variáveis que representam as características familiares. Esse estudo faz uma análise do processo de desenvolvimento da criança tendo como foco as características familiares 


\subsection{Outras perspectivas}

Além da economia, há linhas de pesquisa dentro da sociologia e da psicologia que também estudam o processo de desenvolvimento do indivíduo. Esses estudos buscam descrever às relações entre agentes e instituições. A partir desse conhecimento, os modelos econômicos foram desenvolvidos, com o foco principal em mensurar os determinantes do processo de desenvolvimento da criança.

Os modelos de perspectivas gerais ou de socialização analisam as transferências de conduta entre pais e filhos ao verificar seus comportamentos na sociedade. Os pais e os irmãos mais velhos representam o modelo de conduta, eles são responsáveis por influenciar o comportamento a partir de hábitos, na formação dos objetivos e a composição dos valores. Esses aspectos são definidos como formações cognitivas e psico-social da criança.

Outras teorias como a do trauma e a da cópia de estratégias corroboram o resultado obtido no modelo anterior. Essas teorias acreditam que acontecimentos de difícil aceitação (separação, perda ou desemprego dos pais) são geradores de fortes desequilíbrios na estrutura de formação da criança. O desequilíbrio é decorrente da desestruturação do modelo padrão de conduta da vida, que são representados pelos responsáveis em geral os pais (MCCUBBIN, 1980). Para essas crianças o modelo padrão é a sua realidade, ou aquilo que elas vivenciaram.

Os valores transferidos de forma intrínseca pelos pais (valores morais, hábitos, objetivos de vida, ambições) mesmo considerando-os não adequados ou negativos à conduta humana geral, são absorvidos pela criança como "fato normal"', o que poderá gerar diferenças na formação e no desenvolvimento dela.

Outra abordagem dada pela psicologia assume que os pais podem melhor desenvolver a capacidade de seus filhos caso compreendam que este é um processo cumulativo e que a criança deve ser estimulada de forma adequada em cada fase da vida. Essa teoria foi definida como teoria das fases ou dos ciclos de vida (curso de vida ou sistema natural). O desenvolvimento é resultado da interação entre dois processos simultâneos: o externo e o interno. O estímulo externo é principalmente dados pelos pais. Eles são responsáveis por 
estimular, instigar e criar novos ambientes. Ao receber toda essa informação a própria criança ao lidar e adaptar-se a tais situações desenvolve suas habilidades. Esse processo é divido em fases. Em cada período as crianças respondem aos acontecimentos de forma diferente dentro do limite da habilidade natural de cada idade. No ato de adaptação para o meio é que se faz a realização do desenvolvimento da criança. O desenvolvimento é considerado um processo de ajuste, adaptação e interação do indivíduo aos estímulos externo limitado de acordo com a sua fase. Nessa teoria o papel dos pais é fundamental, pois são responsáveis pela adequação dos estímulos em cada fase (INHELDER; PIAGET, 1958).

Na teoria determinista, o desenvolvimento sofre limitações de acordo com o ambiente em que o indivíduo esta inserido. Por exemplo, indivíduos criados em ambientes com poucas oportunidades acreditam que não podem se desenvolver além dessas fronteiras pré-determinadas por suas próprias condições. Nesse modelo, a própria capacidade do indivíduo é subestimada, dada pela dificuldade da situação (MACAULEY, 1977).

Os estudos que buscam mensurar o impacto das características familiares priorizam as características das mães, pois elas participam de forma mais intensa e direta no processo de desenvolvimentos dos filhos. As principais variáveis utilizadas para definir diferentes padrões de mães são: tipos de trabalho, alocação do tempo e escolaridade. Mães que trabalham dentro do domicílio conseguem monitorar as atividades de seus filhos, apesar da remuneração desse trabalho, em geral, ser baixa. Hetherington, Camara e Featherman (1983) afirmam que existe um tradeoff entre aumento de renda e diminuição na alocação do tempo gasto no cuidado da criança. E em países em desenvolvimento a renda é a variável com maior impacto na qualidade no desenvolvimento da criança devido à falta de estrutura básica fornecida pelo governo.

Com o auxílio do conhecimento dessas outras ciências, intensifica-se a importância das características familiares no processo de formação de capital humano na criança. 


\section{Métodos Econométricos}

Este trabalho tem como objetivo analisar a variável anos de atraso escolar, que apresenta natureza de seu número discreta e não negativa, o que caracteriza dados em contagem.

O método mais simples de mínimos quadrados não representa a forma adequada dos dados pois, revela valores $x \hat{\beta}<0$ (fornece valores negativos de $y$ ). Para solucionar essa questão a solução é procurar por uma distribuição com essas propriedades. A distribuição

que segue esse tipo é a de Poisson. Caso uma variável discreta $Y$ siga a distribuição de Poisson então:

$$
\operatorname{Pr}(Y=y)=\frac{e^{-\lambda} \lambda y}{y !}, \quad y=0,1,2 \ldots
$$

a soma das probabilidades das categorias $(y=0,1,2, .$.$) apresentadas em (4.1) somam$ 1. A distribuição é caracterizada por um único parâmetro $\lambda$. A média e a variância de Poisson para uma amostra com variáveis aleatórias são ambas iguais a $\lambda$, e somente com valores positivos.

\subsection{Modelo de Regressão de Poisson}

Essa seção que descreve a regressão de Poisson segue Davidson e MacKinnon (2004) O modelo básico de regressão de Poisson é obtido substituindo uma função não negativa no parâmetro $\lambda$ em (4.1). A função mais adequada para essa escolha é a função de média exponencial.

$$
\lambda_{t}(\beta) \equiv \exp \left(X_{t} \beta\right)
$$


em que é utilizada a função índice linear $X_{t} \beta$. Para qualquer escolha válida de $\left(\lambda_{t}(\beta)\right)$, obtemos o modelo de regressão de Poisson:

$$
\operatorname{Pr}(Y=y)=\frac{\exp \left(-\lambda_{t}(\beta)\right)\left(\lambda_{t}(\beta)\right)^{y}}{y !}, \quad y=0,1,2 \ldots
$$

O pressuposto intrínseco da distribuição de Poisson se dá sobre os momentos condicionais de $y$, representado pela média e pela variância:

$$
\operatorname{Var}(y \mid x)=E(y \mid x)=\lambda
$$

Caso a variável de contagem observada $t$ é $y_{t}$, então a contribuição para a função log de verossimilhança é o logaritmo do lado direito de (4.3) no ponto $y=y_{t}$. Assim, a função completa de log da verossimilhança é:

$$
l_{y, \beta}=\sum_{t=1}^{n}\left(-\exp \left(X_{t} \beta\right)+y_{t} X_{t} \beta-\log y_{t} !\right)
$$

na qual considera a especificação da média na forma exponencial(4.2), em que $x$ é um vetor $1 \times k$, e $\beta$ é um vetor $k \times 1$.

A maximização da função(4.5) em relação ao parâmetro $\beta$ é a condição de primeira ordem representada por:

$$
\frac{\partial l(y, \beta)}{\partial \beta}=\sum_{t=1}^{n}\left(y_{t}-\exp \left(X_{t} \beta\right)\right) X_{t}=0,
$$

e a partir da segunda derivada é possível construir a matriz Hessiana representada por:

$$
H(\beta)=-\sum_{t=1}^{n} \exp \left(X_{t} \beta\right) X_{t}^{T} X_{t}=-X^{T} \Upsilon(\beta) X
$$

em que $\Upsilon(\beta)$ é uma matriz diagonal $n \times n$ com elemento diagonal típico igual a $\Upsilon_{t}(\beta) \equiv$ $\exp \left(X_{t} \beta\right)$. A inferência é baseada no resultado assintótico padrão que define como a matriz de covariância igual a inversa da matriz de informação, dado por:

$$
\widehat{\operatorname{Var}}(\hat{\beta})=\left(X_{t} \hat{\Upsilon} X\right)^{-1}
$$

em que $\hat{\Upsilon} \equiv \Upsilon(\hat{\beta})$

A regressão de Poisson é o ponto de partida para as análises de dados em contagem pela sua simplicidade, entretanto esse modelo dificilmente é satisfatório. As principais 
limitações da regressão do modelo padrão de Poisson seguem abaixo e são determinantes fundamentais para a escolha de outros métodos alternativos:

- Na prática, apesar do modelo prever a existência de zeros, a variância real do modelo é maior que a variância estimada na modelo de Poisson. Essa falha é definida como overdispersion.

- O modelo de Poisson falha por não incorporar o problema do 'excesso de zeros', mesmo que a distribuição de Poisson seja caracterizada por eventos raros e discretos, a grande quantidade de zeros amostral cria diferença entre a distribuição amostral de Poisson. Para solucionar tal problema, Mullahy (1986) considera que o modelo é composto por duas partes e que cada uma segue uma função de distribuição de probabilidade.

- O modelo é inconsistente na presença de endogeneidade.

O estudo quer analisar o atraso escolar em função das características familiares. Sabese que a variável dependente, a medida do anos de atraso é uma variável discreta e não negativa, por isso é natural a escolha de modelo com especificações de contagem. Entretanto, existe o problema da variável endógena que quando não tratada, gera a inconsistência nos estimadores. A seguir será testada a existência da endogeneidade nesse modelo, a partir do seguinte teste:

- para endogeneidade: verifica se a variável explicativa está correlacionada com o erro, em caso positivo as estimações padrão apresentam parâmetros inconsistentes. O teste na forma individual, utiliza o método de regressão base simples.E para o tratamento conjunto dessas variáveis endógenas utiliza-se a estatística C que é robusta a heteroscedasticidade.

- para sobreidentificação: garante que a relação ortogonal da combinação linear das variáveis instrumentos com o erro é significante. Assim, podemos concluir que os instrumentos utilizados apresentados são bons instrumentos. 
E o teste para heteroscedasticidade determina se a dispersão do estimador é constante. Em geral modelos de contagem apresentam heteroscedasticidade devido à sua natureza. Nesse caso, é importante identificar a existência da heteroscedasticidade, de forma a tratála para que as estatísticas dos outros testes sejam calculadas de forma correta.

\subsection{Testes para heteroscedasticidade, endogeneidade e sobreidentificação}

\section{Teste para heteroscedastidade}

O princípio é testar se o resíduo da regressão e as variáveis indicadoras $p$ estão relacionadas as hipóteses de heteroscedasticidade. Como apresentado em Baum, Schaffer e Stillman (2003), a estatística original tem distribuição $\chi^{2} \operatorname{com} p$ graus de liberdade com a hipótese nula de homoscedasticidade e com a normalidade dos erros. Esse estatística criada por Koenker verificou que o poder do teste era sensível ao pressuposto de normalidade e apresentou uma outra versão que relaxa essa hipótese.

$n R_{c}^{2}$ é facilmente obtido, em que $n R_{c}^{2}$ é centrado no $R^{2}$ da regressão auxiliar dos quadrados dos resíduos da regressão original da variável indicadora. Quando a variável indicadora coincide com os regressores da equação original, seus quadrados e seus produtos cruzados são idênticos ao teste de heteroscedasticidade de White(1980).

Dada $\Psi$, a variável indicadora $\bar{\Psi}=\frac{1}{n} \sum_{i=1}^{n} \Psi_{i}$ é uma matriz indicadora $n \times p$ de variáveis hipoteticamente relacionadas com a heteroscedasticidade. Essas variáveis indicadoras devem ser exógenas, tais como instrumentos ou função dos instrumentos. A escolha feita por White(1980) para variável indicadora são níveis, quadrados e produtos cruzados dos instrumentos $Z$ (excluindo a constante).

O teste assume homoscedasticidade, então $B_{2}=B_{3}=B_{4}=0$ com a estatística $n R_{c}^{2}$.

O conhecimento e a correção da característica heteroscedástica dos dados do modelo permite que os testes e estimações sejam consistentes. A estatística do teste será apresentada na tabela 12 .

\section{Teste para endogeneidade}


A endogeneidade em estimações padrão gera a inconsistência dos parâmetros estimados. A endogeneidade é gerada pela não ortogonalidade entre as variáveis explicativas e o erro. O processo de variáveis instrumentais(VI) tornar a estimação consistente, o tradeoff entre a perda de eficiência. O custo da performance do estimador de VI pode ser visto quando $x$ e $u$ não são correlacionados: a variância assintótica do estimador VI é sempre maior, e as vezes muito maior, que a variância assintótica do estimador MQO (WOOLDRIDGE, 2002). Naturalmente a perda de eficiência é o preço por tornar um estimador viesado e inconsistente em consistente.

A seguir será apresentado o teste de endogeneidade descrito por Wooldridge (2002). Para descrever o teste de forma clara, define-se $y_{1}$ a variável dependente e $y_{2}$ a variável explicativa potencialmente endógena. A variável endógena do modelo não sofre restrição quanto a sua natureza, ela pode ser contínua ou discreta. O modelo populacional é descrito por:

$$
y_{1}=z_{1} \delta_{1}+\alpha_{1} y_{2}+u_{1}
$$

em que $z_{1}$ é $1 \times L_{1}, \delta_{1}$ é definida por $L_{1} \times 1$, e $u_{1}$ é um erro não observável. O conjunto de todas as variáveis exógenas é definido por $\mathbf{z}$, vetor $1 \times L$, em que $z_{1}$ é um subconjunto de variáveis exógenas incluídas no modelo. O pressuposto sobre a exogeneidade é representado por:

$$
E\left(\mathbf{z}^{\prime} u_{1}\right)=0
$$

Para efeito de teste, a condição (4.10) é sempre mantida. Em uma situação em que $E\left(y_{2} u_{1}\right) \neq 0$, assume-se que a equação (4.16) é identificada, se para cada variável endógena do modelo existir uma variável exógena excluída(condição de ordem), é necessário que uma variável em z não esteja em $z_{1}$. A condição de rank é que pelo menos um elemento de $\mathbf{z}$ não em $z_{1}$ seja parcialmente correlacionada com $y_{2}$. A partir dessas hipóteses, desejamos testar a hipótese nula que $y_{2}$ é realmente exógena.

Hausman (1978) criou um teste formal para a endogeneidade, baseado na comparação dos estimadores $\beta_{1} \equiv\left(\delta_{1}^{\prime}, \alpha_{1}\right)^{\prime}$ em MQO e em MQ2E: se $y_{2}$ é não correlacionado com $u_{1}$, as 
estimações de $\beta$ devem apenas ter diferenças no erro amostral. O teste de endogeneidade de Hausman segue a idéia descrita acima.

A forma original da estatística requer grande esforço computacional devido à singularidade de uma matriz da forma quadrática, exceto quando nenhuma variável exógena está presente na equação (4.16). Como sugerido por Hausman (1978) e Hausman (1983), existe uma alternativa, o teste de regressão base que funciona de forma assintoticamente equivalente a proposta pelo teste de Hausman original. A seguir será feita a descrição do teste regressão base, escrito a partir da projeção linear de $y_{2}$ em $\mathbf{z}$ :

$$
\begin{gathered}
y_{2}=\mathbf{z} \pi_{2}+v_{2} \\
E\left(\mathbf{z}^{\prime} v_{1}\right)=0
\end{gathered}
$$

em que $\pi_{2}$ é $L \times 1$. Dado $u_{1}$ não correlacionado com $\mathbf{z}$, e a partir das equações (4.11) e (4.12), $y_{2}$ é considerada endógena se e somente se $E\left(u_{1} v_{2}\right) \neq 0$. Então, podemos testar se o erro estrutural $u_{1}$ é correlacionado com a resíduo da forma reduzida $v_{2}$. A projeção linear de $u_{1}$ pode ser em $v_{2}$, pode ser expressa em função do erro da seguinte forma:

$$
u_{1}=\rho_{1} v_{2}+e_{1}
$$

em que $\rho_{1}=E\left(v_{2} u_{1)} / E\left(v_{2}^{2}\right), E\left(v_{2} e_{1}=0\right)\right.$ e $E\left(z^{\prime} e_{1}\right)=0$ (desde que $u_{1}$ e $v_{2}$ sejam ambas ortogonais a $z$ ). Então, $y_{2}$ é exógeno se e somente se $\rho_{1}=0$. Substituindo a equação (4.13) em (5.1) temos:

$$
y_{1}=z_{1} \delta_{1}+\alpha_{1} y_{2}+\rho_{1} v_{2}+e_{1}
$$

A chave é que $e_{1}$ não é correlacionado com $z_{1}, y_{2}$ e $v_{2}$ por construção. Desta forma, um teste $H_{0}: \rho=0$ pode ser feito a partir do teste padrão $t$ para a variável $v_{2}$ na estimação MQO da regressão (4.14). O problema é que $v_{2}$ é não observada. Apesar disso, os parâmetros da forma reduzida $\pi_{2}$, são facilmente estimados por MQO. $\hat{v}_{2}$ é calculado a partir da forma reduzida do primeiro estágio da regressão de $y_{2}$ por $z$, relembrando que 
$z$ contém todas as variáveis exógenas. Ao substituir $v_{2}$ por $\hat{v}_{2}$, temos a seguinte equação:

$$
y_{1}=z_{1} \delta_{1}+\alpha_{1} y_{2}+\rho_{1} \hat{v}_{2}+\text { erro }
$$

$\delta_{1}, \alpha_{1}$ e $\rho_{1}$ serão estimados de forma consistente por MQO. Os valores estimados de $\delta_{1}$ e $\alpha_{1}$ no segundo estágio apresentado pela equação (4.15) são iguais aos valores obtidos por MQO. Esse fato é conveniente pois além da facilidade computacional do processo, a regressão (4.15) resultante permite comparar as magnitudes entre os estimadores obtidos por MQO e MQ2E. Esse processo ainda permite compreender melhor o processo computacional por trás desse teste.

\section{Teste $C$}

Para o caso de teste conjunto das variáveis endógenas com heteroscedasticidade condicional o teste adequado é a estatística $C$. O teste $C$ testa a combinação linear das condições de ortogonalidade.

Mesmo que a estatística $C$ possa ser calculada pela diferença entre as estatísticas Hansen-Sargan para duas regressões, esse procedimento gera uma estatística teste negativa em amostras finitas. No contexto VI, esse problema pode ser evitado se a estimativa da variância do erro $\hat{\sigma}^{2}$ da equação restrita (mais eficiente) for usada para calcular a estatística Sargan da regressão restrita.

A estatística de Hausman para especificação é numericamente igual ao teste $C$ que testa a combinação linear das condições de ortogonalidade quando a equação é exatamente identificada. Os graus de liberdade da estatística de Hausman na presença de heteroscedasticidade condicional não apresenta forma conhecida. Enquanto a estatística tem graus de liberdade dado por: $C=L^{e}-L^{c}$ em que $L^{e}$ e $L^{c}$ representa respectivamente o número total de instrumentos restrito(eficiente) e não restrito(consistente mas não eficiente).

\section{Teste para as restrições de sobreidentificação}

Quando o modelo apresenta um número maior de instrumentos que são necessários para identificar a equação, podemos testar se o instrumento adicional é válido na medida 
em que ele não está correlacionado com $u_{1}$. Para explicar alguns procedimentos escrevemos novamente a equação (4.16):

$$
y_{1}=z_{1} \delta_{1}+\alpha_{1} y_{2}+u_{1}
$$

em que $z_{1}$ é $1 \times L_{1}$ e $y_{2}$ é $1 \times G_{1}$. O vetor $1 \times L$ de todas as variáveis endógenas continua z. Os vetores são representados por $z=\left(z_{1}, z_{2}\right)$, em que $z_{2}$ é $1 \times L_{2}$ e $L=$ $L_{1}+L_{2}$. O modelo é sobreidentificado, $L_{2}>G_{1}$. Dada a condição de identificação, qualquer subconjunto de $1 \times G_{1}$ pode ser utilizado como instrumento para estimar a equação de $y_{2}$. Seguindo esses princípios, Hausman (1978) sugeriu a comparação dos estimadores de mínimo quadrado de dois estágios que utiliza todos os instrumentos com aqueles estimadores formados por apenas um subconjunto de instrumentos. Caso todos os instrumentos fossem válidos, as estimações deveriam apenas diferir quanto ao resultado do erro amostral. Da mesma forma como dito anteriormente a construção da estatística original de Hausman é computacionalmente complicada. Entretanto, uma outra forma capaz de realizar esse teste de forma simples é o processo de regressão.

Dado $\hat{y}_{2}$, obtido no primeiro estágio, por mínimos quadrados ordinários e $h_{2}$ um vetor $1 \times Q_{1}$ um subconjunto de $z_{2}$ (Não importa quais elementos foram escolhidos, apenas que $Q_{1}$ elementos foram escolhidos). Faça a regressão para cada elemento de $h_{2}$ em relação a $\left(z_{1}, \hat{y_{2}}\right)$ e estime os resíduos,$\hat{r_{2}}\left(1 \times Q_{1}\right)$. Assim, a estatística $\chi_{Q 1}^{2}$ é obtida como $N-S S R_{0}$ da regressão 1 de $\hat{u_{1}} \hat{r_{2}}$. A prova do funcionamento desse método é similar ao teste robusto de heteroscedasticidade para restrições excluídas. A estatística do teste Sargan é:

$$
\text { Sargan }=\frac{1}{\hat{\sigma}^{2}} \hat{u}^{\prime} Z\left(Z^{\prime} Z\right)^{-1} Z^{\prime} \hat{u}=\frac{\hat{u}^{\prime} Z\left(Z^{\prime} Z\right)^{-1} Z^{\prime} \hat{u}}{\hat{u}^{\prime} \hat{u} / n}=\frac{\hat{u}^{\prime} P_{Z} \hat{u}}{\hat{u}^{\prime} \hat{u} / n}
$$

A estatística de Sargan tem a forma $n R_{u}^{2}$ (em que $R_{u}^{2}$ é o $R^{2}$ não centrado), e como descrito anteriormente, pode ser facilmente calculado pelo resíduo da equação VI sobre todos os instrumentos (ambas variáveis exógenas e exógenas excluídas(instrumentos)). 


\subsection{Método de variáveis instrumentais}

O método de variáveis instrumentais é utilizado para contornar o problema de endogeneidade. Da mesma forma como descrito por Davidson e MacKinnon (2004), inicia-se com a apresentação do modelo padrão MQO, como forma de justificar a utilização do método de variáveis instrumentais. No modelo de regressão linear:

$$
\begin{gathered}
\exp (x \alpha)+\Theta+\epsilon, \\
y=X \beta+u, \quad E\left(u u^{T}\right)=\sigma^{2} I,
\end{gathered}
$$

em que pelo menos uma das variáveis explicativas da matrix $\mathbf{X}$ de ordem $n \times k$ é assumida como não pré-determinada com relação aos termos de erro. E suponha que para cada $t=1, \ldots, n$ a condição

$$
E\left(u_{t} \mid \Omega_{t}\right)=0
$$

é satisfeita para um conjunto de informações $\Omega_{t}$ e que formará uma matriz $\mathbf{W}$ com o número de linhas $t \mathbf{W}_{t}$ tais que todos os seus elementos pertencerão a $\Omega_{t}$. A variável $k$ formada pelas $k$ colunas de $\mathbf{W}$ são chamadas de variáveis instrumentais, ou simplesmente de instrumento.

As variáveis instrumentais podem ser exógenas pré-determinadas, e por razões que serão explicadas posteriormente, sempre devemos incluir todas as colunas de $\mathbf{X}$ no primeiro estágio do processo. Existem muitas controvérsias empíricas nas disputas de validade da constituição das variáveis instrumentais.

Para o modelo linear 4.19, a condição de momento é:

$$
W_{T}(y-X \beta)=0
$$

Desde que exista $k$ equações e $k$ exógenas, podemos resolver a equação de forma direta ao obter de forma direta o estimador de variáveis instrumentais simples dado por:

$$
\hat{\beta}_{I V}=\left(W^{T} X\right)^{-1} W^{T} y
$$


A condição que esse estimador deverá seguir é se $W_{t} \in \Omega_{t}$,

$$
E\left(u_{t} \mid \Omega_{t}\right)=0
$$

Essa suposição mostra que $W_{t}$ é não correlacionado em relação ao termo erro. Ao considerar a suposição 4.21 o estimador $\hat{\beta}_{I V}$ é consistente e assintoticamente normal sob condição de identificação. A def inição assintótica da variância de $W^{T} X$ pode ser escrita como:

$$
S_{W^{T} X} \equiv P \lim _{n \rightarrow \infty} \frac{1}{n} W^{T} X
$$

em que a equação acima é determinada e não-singular. Para qualquer amostra identificada, a condição necessária é $W_{T} X$ não-singular. Caso essa condição não seja satisfeita, a equação (4.21) não terá solução única.

A partir da equação abaixo o estimador é consistente se o modelo for corretamente especificado e a condição (4.22) for imposta:

$$
\begin{aligned}
\hat{\beta}_{I V} & =\left(W^{T} X\right)^{-1} W T X \beta_{0}+\left(W^{T} X\right)^{-1} W T u, \\
& =\beta_{0}+\left(n^{-1} W^{T} X\right)^{-1} n^{-1} W^{T} u
\end{aligned}
$$

Ou ainda dado a variância assintótica, $\hat{\beta}_{I V}$ é consistente se:

$$
P \lim _{n \rightarrow \infty} \frac{1}{n} W^{T} u=0
$$

a condição mantém o termo de erro assintoticamente não correlacionado com os instrumentos. A condição descrita acima é a condição fraca para atingir a consistência do estimador IV.

O modelo em questão "anos de atraso escolar" viola as duas principais hipóteses do modelo de Poisson devido às característica dos dados. A primeira hipótese violada foi a relação entre a média e a variância condicional provocada pelo excesso de números zeros na variável dependente anos de atraso escolar e a segunda é a endogeneidade da variável anos de educação da mãe. Por isso, métodos alternativos serão apresentados para que 
parâmetros consistentes sejam estimados.

\subsection{Alternativas para o modelo de Poisson}

Iniciaremos a discussão do fenômeno de overdispersion. A forma mais direta de remover esse problema é retirar a restrição (4.4) ao assumirmos uma função densidade probabilidade menos restritiva. Ou ainda, adicionar um parâmetro de overdispersion $\phi$, com a interpretação que o overdispersion é resultado de uma heterogeneidade não observada que fora negligenciada quando o modelo foi formado, o que justificaria o tratamento do parâmetro de Poisson como uma variável aleatória. Desta forma, adicionar um termo à média condicional de $y$ é equivalente a introduzir um termo de erro de forma multiplicativa na função de média condicional. Acatando tais mudanças temos em (4.2):

$$
\lambda_{t}(\beta)=E\left(y_{t} \mid x_{t}, \nu_{t}\right)=\exp \left(x_{t}^{\prime} \beta+\varepsilon_{t}\right)=\exp \left(x_{t} \beta\right) \cdot \nu_{t}
$$

em que a heterogeneidade não observada expressa pelo termo $\nu t=\exp \left(\varepsilon_{t}\right)$ pode refletir um erro de especificação. Assume-se que $\nu_{t}$ são independentes e identicamente distribuídas, e que são independentes do termo $x$, ou seja, não existe problema de endogeneidade.

Ao assumir que $E\left(\nu_{t}=1\right), \operatorname{var}\left(\nu t=\sigma_{t}^{2}\right.$ e $E\left(y_{t} \mid x_{t}, \nu_{t}\right)=\operatorname{var}\left(y_{t} \mid x_{t}, \nu_{t}\right)$, então, os momentos de $y$ condicionais a $x$, podem ser expressos por:

$$
E\left(y_{t} \mid x_{t}\right)=\exp \left(x_{t}^{\prime} \beta\right)
$$

e

$$
\operatorname{var}\left(y_{t} \mid x_{t}\right)=\exp \left(x_{t}^{\prime} \beta\right)\left[1+\sigma_{t}^{2} \cdot \exp \left(x_{t}^{\prime} \beta\right)\right]>E\left(y_{t} \mid x_{t}\right)
$$

Assim, o método de quase-verossimilhança apresentado acima desenvolvido por Cameron e Trivedi (1990) permite obter parâmetros consistentes quando todas as distribuições de $g\left(\nu_{t}\right)$ tiverem segundo momento, sem que haja a necessidade de assumir uma distribuição mista.

Outra alternativa para a estimação consistente de dados em contagem com overdis- 
persion é o método de máxima verossimilhança. Esse método para atingir resultados consistentes assume especificação total da distribuição. Nesse caso, é assumido uma distribuição mista com heterogeneidade gamma não observada e distribuição binomial negativa, no qual é parametrizada da seguinte forma:

$$
\begin{array}{r}
h\left(y_{t}\right)=\left(\frac{\Gamma\left(y_{t}+\psi_{t}\right)}{\Gamma\left(\psi_{t}\right) \Gamma\left(y_{t}+1\right)}\right)\left(\frac{\psi_{t}}{\lambda_{t}+\psi_{t}}\right)^{\psi_{t}}\left(\frac{\lambda_{t}}{\lambda_{t}+\psi_{t}}\right)^{y_{t}} \\
y_{t}=0,1,2,3
\end{array}
$$

em que $\lambda_{t}$ é a média e $\psi_{t}^{-1}$ é um parâmetro. A forma exata da distribuição mista deve estar próxima da expressão correta e depende da escolha específica de $g\left(\nu_{t}\right)$. E para manter a propriedade geral de $g\left(\nu_{t}\right)$ não dependem se há ou não overdispersion.

Nesse contexto, existem várias possibilidades de especificação das relações entre a média e a variância. Quando a media é especificada a partir da forma:

$\lambda_{t}=\exp \left(x_{t}^{\prime} \beta\right)$ e $\psi_{t}=(1 / \alpha) \lambda_{t}^{k}$ entende-se que $\alpha>0$ mostra uma dispersão do parâmetro e $k$ é uma constante arbitrária.

O modelo binomial negativo segue a especificação da média e variância, respectivamente:

$E\left(y_{t} \mid x_{t}\right)=\lambda_{t}$ e a var $=\left(y_{t} \mid x_{t}\right)=\lambda_{t}+\alpha \lambda_{t}^{2-k}$. Os modelos mais comuns são Negbin1 e Negbin2, e que são obtidos respectivamente quando $k=0$ e $k=1$. O modelo Negbin1 implica em uma função da variância de forma linear em relação a média $\lambda$ enquanto Negbin2 implica em uma função variância quadrática. O modelo de regressão de Negbin é amplamente utilizado como alternativa para o modelo de Poisson por também acomodar o overdispersion. Misturar termos de heterogeneidade não observada de forma multiplicativa não afeta a média condicional, e ainda torna flexível a relação entre média e variância.

Além disso, misturar termos de heterogeneidade não observada gera aumento da proporção de zeros na observação, ou seja, aumenta a freqüência das categorias com maiores pesos. Assim, a função distribuição de probabilidade com heterogeneidade não observada mista cria aparentemente uma distribuição em duas partes. 
Por exemplo, caso os eventos reflitam a escolha individual, a possibilidade de ocorrência de soluções de canto são maiores que a própria solução da média de Poisson $(\lambda)$. Em muitos casos aplicados os efeitos da heterogeneidade não observada não estão restritos às especificação da variância, e portanto podem ser utilizados para generalizar ou modificar a especificação de ambos da média e da variância.

A seguir serão apresentados os métodos de quase verossimilhança em dois estágios para a função binomial negativa e de máxima verossimilhança para o modelo Hurdle com zeros inflados que também utilizam a função binomial negativa para representar os dados em contagem.

\subsection{Estimação por Quase Verossimilhança em dois estágios}

Uma abordagem apropriada para esse modelo é a quase verossimilhança em dois estágios. O próprio nome indica que o método utilizado é baseado na estimação por máxima verossimilhança. Esse método para atingir a consistência dos seus estimadores assume que as covariadas sejam independentes. Entretanto, o modelo estudado apresenta uma variável endógena, e a forma de tratamento dessa variável é estimá-la em um primeiro estágio a partir de seus instrumentos que nesse caso são os anos de estudos dos pais da mãe e do pai.

Primeiramente, assume-se uma forma reduzida para a estimação da variável endógena(anos de estudos da mãe) em função dos instrumentos e das outras variáveis exógenas, da seguinte forma:

$$
\begin{aligned}
x & =z R \Delta+v \\
& =z+v
\end{aligned}
$$

em que $R$ é uma matriz de ordem $p \times p$ que define a priori restrições para a matriz de parâmetros $\Delta$ de ordem $p \times k$. Para a equação ser ao menos identificada a regressão que estimará $\hat{x}$, deve conter para cada variável endógena ao menos uma variável exógena excluída. Para o modelo ser considerado identificado deve seguir $\operatorname{rank}(\delta)=k \operatorname{com}(p \geq k)$. 
Para simplificar, assume-se a forma linear entre a variável endógena e o instrumento $E(x \mid z)$. Desta forma, torna se possível estimar a variável endógena em função dos instrumentos por mínimos quadrados ordinários(MQO). Essa estimação é feita da seguinte forma: $\hat{x}=z \hat{\delta}$. A partir do resultado anterior de $\hat{x}$ é possível compor a função de quase-verossimilhança que assume forma desconhecida da função da variância.

Assume-se que $E[\exp (x c) \nu \mid z]=0$, para qualquer vetor finito com $c$ constante, ou seja, o vetor instrumento $z$ é independente de $\nu$ e $x$. Substituindo-se a forma reduzida de $x$ em $\lambda(x, \nu ; \beta)$ temos:

$$
\begin{aligned}
\lambda(x, \Theta ; \beta) & =\exp (x \beta) \nu \\
& =\exp [(z \delta) \beta+v \beta] \nu \\
& =\exp (z \theta+\xi) \\
& =\lambda(z, \xi ; \theta)
\end{aligned}
$$

em que $\Theta=\log \nu$ em que $\theta=\delta \beta(p \times 1)$ e $\xi=v \beta+\log \nu$. Ao assumir por hipótese que $E(\exp \xi \mid z)=0$, as estimativas de quase-verossimilhança feitas a partir de $\lambda(z, \xi ; \theta)$ serão consistentes. Isso porque de forma direta quando o parâmetro do estimador endógeno é calculado no primeiro estágio, este é responsável por garantir a consistência e portanto, permite que a estimação de quase-verossimilhança mantenha o parâmetros consistentes.

\subsection{Modelos de contagem modificados: Modelo Hurdle que segue zeros inflados}

O problemas de excessos de zeros pode ser resolvido a partir da transformação do modelo de contagem, que segue distribuição binomial negativa devido ao problema de overdispersion.

O modelo hurdle assume duas distribuições de probabilidade para y, ou seja, relaxa a hipótese que os zeros e os outros valores positivos são gerados a partir do mesmo processo gerador de dados. Os zeros são determinados pela densidade $f_{1}(\cdot)$, então $\operatorname{Pr}[y=0]=$ $f_{1}(0)$. As categorias positivas são representadas pela densidade truncada $f_{2}(y \mid y>0)=$ 
$f_{2} /\left(1-f_{2}(0)\right)$, o qual é multiplicado por $\operatorname{Pr}[y>0]=1-f_{1}(0)$ para garantir que a soma das probabilidades individuais seja igual um. Então:

$$
g(y)= \begin{cases}f_{1}(0) & \text { se } \mathrm{y}=0 \\ \frac{1-f_{1}(0)}{1-f_{2}(0)} f_{2}(y) & y \leq 1\end{cases}
$$

Esse processo se reduz ao modelo padrão apenas se $f_{1}(\cdot)=f_{2}(\cdot)$. No modelo modificado o processo gerador de dados é diferente para cada parte.

A estimação por máxima verossimilhança dos modelos hurdle envolve função verossimilhança representada em duas partes, um correspondente aos zeros e o outro referente aos valores positivos. Esse modelo hurdle interpreta que o processo de tomada de decisões é feito em dois estágios.

A aplicação do modelo hurdle é obtida a partir das especificações da função densidade $f_{1}(\cdot)$ e $f_{2}$ que segue função densidade binomial negativa. Na prática as covariadas nas duas partes não necessitam seguir os mesmos valores.

A idéia básica é que a probabilidade binomial permite direcionar o modelo para estimações das categorias zero ou para as outras com valores positivos. Caso a realização da variável seja positiva, a distribuição condicional segue especificações adequadas para variáveis positivas e portanto segue um modelo de dados de contagem truncado no valor zero.

O modelo hurdle ao utilizar a função binomial negativa incorporou relações mais gerais quando comparada ao modelo de Poisson. Desta forma, consegue contornar o problema de overdispersion, mas devido à variável endógena do modelo a estimação dos parâmetros é inconsistente.

A distribuição dada em (4.26) $\operatorname{com} k=0$ segue as probabilidades:

$$
\begin{gathered}
P_{1}\left(y_{t}=0 \mid x_{t}\right)=\left(1+\alpha_{1} \lambda_{1 t}\right)^{\frac{-1}{\alpha_{1}}} \\
1-P_{1}\left(y_{t}=0 \mid x_{i}\right)=\sum_{y \epsilon \omega} h\left(y_{t} \mid x_{t}\right)=1-\left(1+\alpha_{1} \lambda_{1 t}\right)^{\frac{-1}{\alpha_{1}}}
\end{gathered}
$$




$$
\begin{array}{r}
P_{2}\left(y_{t} \mid x_{t} ; y_{t}>0\right)=\left(\frac{\Gamma\left(y_{t}+\alpha_{2}^{-1}\right)}{\Gamma\left(\alpha_{2}^{-1}\right) \Gamma\left(y_{t}+1\right)}\right)\left(\frac{1}{\left(1+\alpha_{2} \lambda_{2 t}\right)^{\frac{1}{\alpha_{2}-1}}}\right) \times\left(\frac{\lambda_{2 t}}{\lambda_{2 t}+\alpha_{2}^{-1}}\right)^{y_{t}} \\
y_{t} \in \omega
\end{array}
$$

A equação (4.27) direciona a função densidade de probabilidade para a parte com dados zeros e a equação (4.28) é responsável por direcionar para as probabilidades das outras categorias. A equação (4.29) é a distribuição binomial negativa que é truncada no valor zero. E a sua função densidade é:

$$
\left[P_{1}\left(y_{t}=0 \mid x_{t}\right)\right]^{1-I_{t}} \times\left[\left(1-P_{1}\left(y_{t}=0 \mid x_{t}\right)\right) P_{2}\left(y_{t} \mid x_{t}, y t>0\right)\right]^{I_{t}}
$$

O modelo de Poisson hurdle estudado por Mullahy (1986) é obtido a partir da equação (4.27) a (4.30) que considera $\alpha_{1}=\alpha_{2}=0$. A equação (4.30) é a composição da função de log-verossimilhança em duas partes em que ambas são representadas pela função probabilidade binomial negativa. O lado direito é censurado no ponto 1 e o esquerdo truncado no zero. Na prática a maximização da função log verossimilhança computacionalmente é equivalente a maximização da função de verossimilhança feita em duas etapas separadamente da seguinte forma:

$$
\begin{gathered}
\log L_{h 1}\left(\beta_{1}, \alpha 1\right)=\sum_{i}\left(1-I_{t}\right) \times \log \left[P_{1}\left(y_{t}=0 \mid x_{t}\right)\right]+I_{t} \times \log \left[\left(1-P_{1}\left(y_{t}=0 \mid x_{t}\right)\right)\right] \\
\log L_{h 2}\left(\beta_{2} ; \alpha 2\right)=\sum_{t} I_{t} \times \log \left[P_{2}\left(y_{t} \mid x_{t}, y_{t}>0\right)\right]
\end{gathered}
$$

Os estimadores do modelo hurdle são calculados a partir da maximização da função de verossimilhança. O método descrito acima estima parâmetros inconsistentes na presença de variável endógena. 


\section{Resultados Empíricos}

\subsection{Descrição dos Dados}

Os dados da Pesquisa Nacional por Amostragem de Domicílio (PNAD), feito pelo Instituto Brasileiro de Geografia e Estatística (IBGE) forneceram as informações utilizadas nesse estudo.

A PNAD é uma pesquisa feita anualmente com exceção dos anos em que são realizados os Censos demográficos. A PNAD contempla um questionário semelhante ao do Censo, a diferença entre as duas é que a primeira é feita a partir de uma seleção amostral dos domicílios enquanto a segunda é total. A escolha pela PNAD 96, ao invés da mais recente, foi feita principalmente por dois motivos: a existência de dados essenciais e exclusivos nesse ano e a questão sobre política educacional adotada a partir de 96, que afetaram os dados sobre o atraso escolar.

O dado essencial em questão faz parte do suplemento de mobilidade social, exclusivo dos anos de 96 e de 82 . Esse anexo nos fornece os anos de estudos dos pais do chefe de família e do cônjuge. Ou seja a partir desses dados torna-se possível determinar os anos de estudos dos pais dos pais (avós). Essa variável é utilizada como instrumento para a variável "anos de estudos da mãe".

A variável "anos de estudos da mãe" apresenta problema de endogeneidade, pois uma variável não observada definida como habilidade influencia o processo de educação da mãe e o nível de atraso escolar. Assim, quando a variável explicativa e o erro estão correlacionados a estimação padrão de mínimos quadrados ordinários gera estimadores inconsistentes. Para esse modelo uma alternativa é o uso de variáveis instrumentais. 
Outra vantagem desse banco de dados de 96 é a representatividade da variável anos de atraso escolar como medida indicativa de desempenho escolar. Em 1996, foi aprovada a nova lei de diretrizes e base da educação que incluiu uma medida (progressão continuada) que visa a melhoria do fluxo escolar. O objetivo dessa iniciativa é manter o aluno na escola, de forma que a reprovação não seja a causa do abandono escolar. Acredita-se que essa medida é o primeiro passo para elevar a qualidade educacional. Os defensores dessa medida acreditam que manter o aluno na escola é o fator que gera maior contribuição para ao longo da formação do indivíduo.

Alguns educadores questionam essa medida e alegam que ela seria responsável por causar uma queda na qualidade efetiva na formação dos alunos, mesmo que o nível médio da educação dos indivíduos aumente. Paro (2003) confirma tal afirmação pois acredita que o fato de repetir a mesma série é uma maneira de disciplinar e educar a criança, e repetir faz parte do processo como um todo. Entretanto, o estudo recente sobre a progressão continuada feito por Menezes-Filho, Vasconcellos e Ribeiro (2005) verificou que a qualidade do ensino dos alunos não sofreu alterações após a adoção dessa medida. Independentemente da questão da qualidade, a progressão continuada entretanto diminuiu os índices de atraso escolar.

Os dados da PNAD 2004 evidenciam que quase 80\% dos jovens entre 7 e 17 anos estão na categoria zero ano de atraso, enquanto em 96 essa proporção estava em 60\%. Ou seja, a partir do pressuposto que a qualidade do ensino se manteve nos mesmos patamares e verificado que ocorreu uma variação bastante significativa na variável atraso escolar durante esse período, acredita-se que atualmente ela não pode ser mais considerada como um indicativo da desempenho escolar. Para analisar o impacto das características familiares em um dos índices de desempenho escolar preferiu-se adotar os dados da PNAD de 1996.

A amostra total da PNAD 96 é composta por 331.263 observações. O objetivo do estudo é analisar o desempenho escolar das crianças e dos adolescentes e para isso foi feito uma sub-amostra composta de 80.040 observações. Essas observações correspondem às crianças e aos adolescentes entre 7 a 17 anos de idade que estão em idade escolar e que 
em geral, ainda vivem na residência com mãe ${ }^{1}$

O banco de dados não fornece a escolaridade da mãe e do pai de cada criança diretamente. Para cada criança da amostra foi criada uma variável nível educacional dos pais pois na pesquisa a pergunta sobre o nível de escolaridade é feita apenas no nível do indivíduo. A estratégia para esse caso foi identificar os indivíduos que compõem uma mesma família através da construção de uma chave ${ }^{2}$. A partir da identificação das pessoas da mesma família e sabendo o código da condição de cada indivíduo dentro dela ${ }^{3}$, pode-se construir uma variável que determina os anos de estudos da mãe e do pai de cada criança.

Entretanto, a informação que determina a condição de filho na família apenas apresenta que ele é filho da pessoa de referência, não que seja o filho do cônjuge da pessoa de referência. Assim, pode-se identificar que o indivíduo é filho do chefe de família, não ficando evidente que o cônjuge não é necessariamente a mãe(caso o chefe seja o pai) ou o pai(caso o chefe seja a mãe). Mesmo assim, no estudo considerou-se que o casal por conter pelo menos um das partes sendo os pais biológicos, o parceiro também desempenhará um papel na formação da criança. Aceita-se essa relação pois a influência social é o fator determinante dos incentivos em capital humano.

A variável educação dos pais dos pais está presente no suplemento da PNAD 96 e fornece essas informações somente para as pessoas com mais de 15 anos de idade. Para identificar os pais dos pais, estabeleceu-se a mesma convenção utilizada para encontrar os pais da criança. Por exemplo, a partir dos critérios anteriores uma mulher foi reconhecida como mãe da criança, essa mãe terá a informação sobre a escolaridade de seus pais e assim podemos estabelecer o nível de escolaridade dos pais dela como sendo a educação dos avós materno.

A construção da variável anos de atraso escolar baseia-se na classificação dos anos de atraso a partir da diferença entre a idade atual menos a idade padrão de entrada da criança

\footnotetext{
${ }^{1}$ Dados da PNAD96 mostram que $93,10 \%$ das pessoas entre 7-17 anos vivem no mesmo domicílio com a mãe

${ }^{2}$ a chave formada pela composição das seguintes variáveis referentes a unidade federativa (UF) + variável controle (v0102) + variável série (v0103) + número da família (v0403)

${ }^{3}$ por exemplo, (1) pessoa de referência, (2) cônjuge do chefe(pessoa de referência), (3)filho da pessoa de referência
} 
na escola. Esse cálculo pode ser desenvolvido de forma direta pois os anos de escolaridade declarados são anos completos até a data da pesquisa que ocorre em setembro. Para avaliar que a sua construção foi feita de forma correta verificaremos as possibilidades. Uma criança com oito anos de idade completos até a data da pesquisa deve estar matriculada na segunda série e declara que tem um ano de escolaridade completo para assim ser classificado com zero ano de atraso escolar. O resultado da diferença entre oito e sete é um, ou seja, essa criança está classificada com zero ano de atraso escolar. O nível de escolaridade declarado são os anos completos de estudos, o mês que a criança nasceu não afeta no cálculo do atraso escolar. Para a criança que faria nove anos(aniversário em outubro, novembro ou dezembro) até o fim do ano, mas declarou oito, na pesquisa deve estar no mínimo cursando a segunda série, o cálculo da escolaridade continuará sendo um o que o classificará com zero ano de atraso escolar caso declare um ano de escolaridade completo. Desta forma, como a pesquisa ocorre em setembro e a escolaridade declarada são os anos completos de estudo a simples diferença permite a classificação em patamares dos alunos em anos de atraso escolar.

Tabela 1: Descrição das variáveis do estudo

\begin{tabular}{lcccc}
\hline variável & média & desvio-padrão & min. & máx. \\
\hline idade da criança & 12,08 & 3,14 & 7 & 17 \\
renda familiar & 784,05 & 1282,87 & 0 & 63500 \\
horas trabalhadas da mãe** & 0,84 & 1,48 & 0 & 5 \\
região nordeste & 0,343 & 0,48 & 0 & 1 \\
região sudeste & 0,31 & 0,46 & 0 & 1 \\
região sul & 0,15 & 0,36 & 0 & 1 \\
região centro oeste & 0,09 & 0,29 & 0 & 1 \\
região norte & 0,09 & 0,28 & 0 & 1 \\
área urbana & 0,72 & 0,45 & 0 & 1 \\
gênero masculino & 0,50 & 0,50 & 0 & 1 \\
raça negra & 0,52 & 0,50 & 0 & 1 \\
educação da avó materna* & 1,92 & 1,41 & 1 & 10 \\
educação do avô materno* & 2,09 & 1,57 & 1 & 10 \\
educação da avó paterno* & 1,90 & 1,41 & 1 & 10 \\
educação do avô paterno* & 2,09 & 1,57 & 1 & 10 \\
educação da mãe* & 3,58 & 2,25 & 1 & 9 \\
educação do pai* & 3,53 & 2,30 & 1 & 9 \\
número de irmãos & 3,14 & 2,51 & 0 & 11 \\
anos de atraso escolar & 1,16 & 1,80 & 0 & 9 \\
\hline *por nível de escolaridade & & & & \\
**por categoria & & & & \\
\hline Fonte:PNAD 1996 & & & & \\
\hline
\end{tabular}


A partir da 1 verifica-se os valores médios apresentados por cada uma das variáveis que compõem o estudo, bem como seu desvio-padrão e os seus valores máximo e mínimo. As descrições das variáveis foram separadas em grupos relevantes, são eles: características individuais das crianças e jovens, características geográficas e características familiares.

- Características individuais das crianças e jovens:

- variável gênero masculino da criança/jovem, com valor 1 para os meninos.

- variável raça negra, composta pelas categorias auto-declarada preta, parda o indígena representada pelo valor 1, e aqueles que se auto-declaram raça branca e amarela tem o valor que os representa igual a 0.

- variável idade da criança/jovem que nesse estudo pertencem ao intervalo de 7 a 17 anos.

- Características geográficas:

- variável área urbana com valor um para as categorias localizadas na área metropolitana, e zero para área rural.

- variável binária para cada região, Nordeste, Norte, Centro-Oeste, Sul e Sudeste. Para cálculo das estimações optou-se por colocar como referência a região Sudeste.

- Características familiares:

- variável categórica que representa a educação da mãe/educação do pai segue os níveis:

* 1- sem nenhuma escolaridade

* 2 - ensino básico incompleto

* 3 - ensino básico completo

* 4 - ensino fundamental incompleto

* 5 - ensino fundamental completo

* 6 - ensino médio incompleto 
* 7 - ensino médio completo

* 8 - ensino superior incompleto

* 9 - ensino superior completo ou mais

- variável da educação da avó/avô materna e educação do avó/avô paterno também é categórica e segue a classificação acima com uma categoria a mais que separa aqueles com ensino superior completo - nível 9 e pós ensino superior $-10$.

- variável contínua renda familiar que equivale ao valor informado no questionário como total da renda familiar composta por salários e outras formas de rendimento. A renda familiar média é $R \$ 784,05$, com um alto desvio-padrão ( $R \$ 1282,87)$, o que representa a concentração de renda.

- variável irmão é formado a partir da informação do número de filhos de cada mãe menos 1. Supõem-se irmão apenas da mesma mãe. A média de irmão no Brasil é de 3,14 crianças.

- variável horas trabalhadas pela mãe é categórica e segue a classificação abaixo.

* '1' para até 14 horas semanais.

* '2' de 15 a 39 horas semanais.

* '3' de 40 a 44 horas semanais.

* '4' de 45 a 48 horas semanais

* '5' para 49 ou mais horas semanais.

A distribuição dos anos de atraso escolar é apresentada pelo histograma (5.1) em que, 59, 97\% das crianças/jovens estão na série adequada(zero anos de atraso escolar). O resultado mostra que são quase $40 \%$ das crianças com defasagem idade-série, esse dado indica a baixa qualidade dos alunos em conseqüência de falhas no funcionamento do processo educacional. 13, 52\% e 9,63\% são as proporções apresentadas nas categorias um ano e dois anos de atraso escolar respectivamente. As categorias com mais de dois anos de atraso seguem proporção decrescente. 


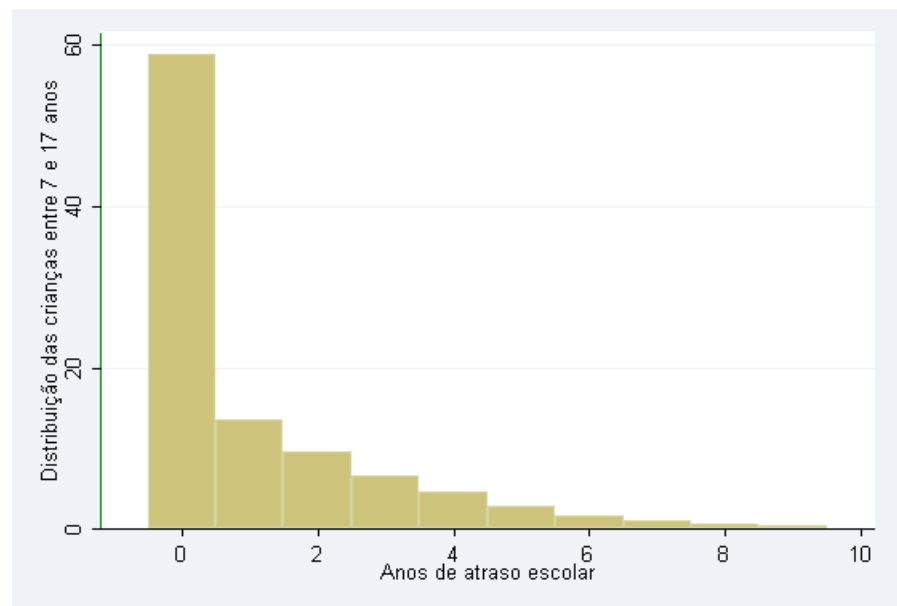

Figura 2: Distribuição dos anos de atraso escolar

Tabela 2: Distribuição das variáveis qualitativas entre regiões

\begin{tabular}{lcccccc}
\hline Região & Prop.Negros & $\begin{array}{c}\text { Educação } \\
\text { da mãe* }\end{array}$ & $\begin{array}{c}\text { Educação } \\
\text { do pai* }\end{array}$ & $\begin{array}{c}\text { Média do anos } \\
\text { de atraso }\end{array}$ & $\begin{array}{c}\text { Número médio } \\
\text { de irmãos }\end{array}$ & $\begin{array}{c}\text { Renda familiar } \\
\text { média }\end{array}$ \\
\hline Norte & 0,75 & 3,70 & 3,51 & 1,30 & 3,77 & 720,12 \\
Nordeste & 0,72 & 3,10 & 2,92 & 1,72 & 3,87 & 521,64 \\
Sudeste & 0,41 & 3,83 & 3,89 & 0,83 & 2,70 & 951,41 \\
Sul & 0,15 & 3,96 & 4,056 & 0,66 & 2,52 & 958,63 \\
Centro Oeste & 0,57 & 3,86 & 3,75 & 1,00 & 2,70 & 930,89 \\
\hline
\end{tabular}

*por nível de escolaridade

Fonte: PNAD 1996

Os anos médios de atraso escolar nacional atingem o patamar de 1,16 anos, identificando de forma bruta, uma falha no processo educacional. Esse valor pode ser mais representativo quando distribuído entre regiões, como apresentado na tabela(2). A região $\operatorname{Sul}(0,66$ ano de atraso escolar) obteve melhor desempenho, enquanto o pior resultado foi apresentado pelo nordeste que tem média quase três vezes maior(1,72). Nessa tabela, podemos verificar que a ordem de melhor desempenho escolar estabelecida por Sul, Sudeste, Centro-Oeste, Norte e Nordeste corresponde a mesma ordem para a melhor renda familiar média, para maior educação média dos pais e para uma menor quantidade de irmãos. Apenas para o nível médio de escolaridade das mães existe uma troca entre as posições centro-oeste e sudeste. Nota-se que existe uma correlação entre a composição das raças e os índices de boas condições de vida. Regiões com maiores concentrações de pessoas com a raça negra apresentam os piores índices de desempenho escolar seguem a mesma ordem acima para as outras variáveis.

A figura (5.1) mostra a proporção de meninos em cada um dos anos de atraso escolar 


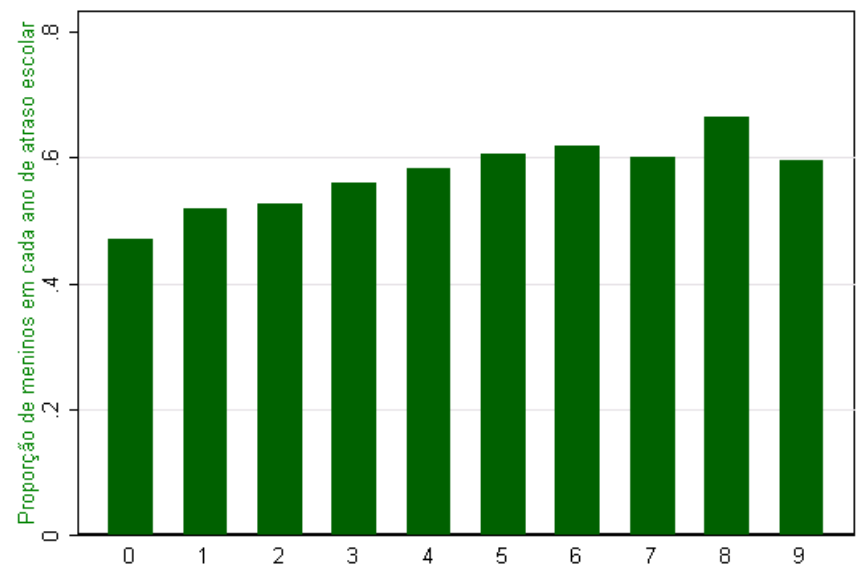

Figura 3: Proporção dos homens em relação as categorias de anos de atraso escolar

entre as crianças/jovens de 7 a 17 anos e verifica-se que elas seguem proporções crescentes. Para zero anos de atraso escolar, 47, 03\% são meninos. Essa proporção cresce para 51, 93\% para um ano de atraso escolar e segue tendência de crescimento que atinge $66,43 \%$ em 8 anos de atraso escolar. A justificativa para essa tendência, é que o custo oportunidade dos meninos para manter-se na escola é grande devido a entrada no mercado de trabalho. Quanto maior a idade menor são as chances de estarem com zeros anos de atraso, os dados mostram que 51,87\% dos meninos com 7 anos tem zero anos de atraso escolar e essa proporção diminui para 41,42\% quando esses estão com 17 anos.

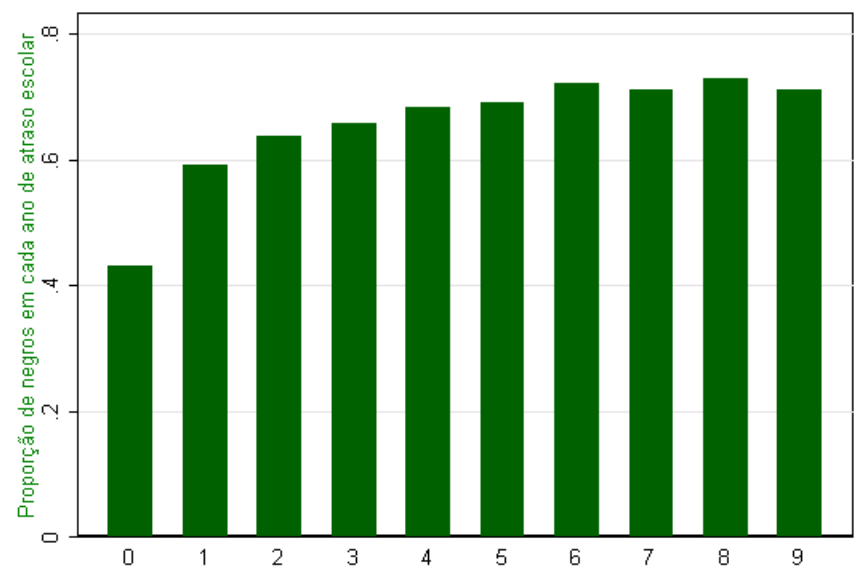

Figura 4: Proporção dos negros em relação as categorias de anos de atraso escolar

A partir da figura(5.1) verificamos que na categoria zero ano de atraso escolar apenas 43, $11 \%$ pertencem a raça negra. As outras categorias( $u$, dois, três, . . . anos de atraso escolar) indicam existência de alguma falha no processo educacional. Para essas categorias, 
por exemplo para um ano de atraso escolar a proporção daqueles com raça negra sobe para quase $60 \%$ (59,05\%). Dado que a proporção de negros e brancos na população amostral é equivalente (51,76\% são negros), esse dados indicam que existem uma desigualdade entre as raças e que aqueles que estão alocados na raça negra a qual possui piores qualificações.

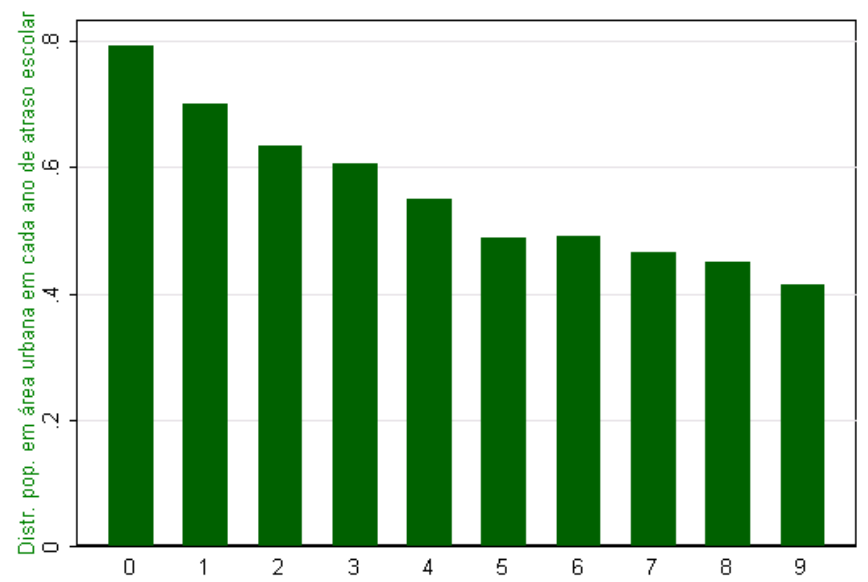

Figura 5: Proporção de indivíduos que moram na área urbana em relação as categorias de anos de atraso escolar

Na figura (5.1) é possível verificar que quase $80 \%(79,31 \%$ ) das crianças que residem em área urbana estão com zero anos de atraso escolar. Esses valores indicam que o desempenho das crianças são melhores nas áreas urbanas, apenas $20 \%$ sofrem deficiência no processo. Assim, dentre as 58, 97\% das crianças que têm zero anos de atraso escolar, 80\% delas estão nas áreas urbanas. Esse resultado corrobora a informação que os investimento e o acesso a educação são melhores em centros urbanos.

Na tabela (3) é feita a correlação entre as variáveis ano de atraso escolar e aquelas que sinalizam melhores habilidades dos pais. Entre elas estão o nível de educação dos pais, mães e avós além dos números de filhos. Entende-se que as pessoas com melhor nível educacional apresentam melhores níveis de desenvolvimentos pessoal geral, que colaboram para melhores cuidados no processo de desenvolvimento das crianças. A quantidade de irmãos, de forma simplificada, sinaliza o rateio de tempo que cada pai/mãe dedica-se a cada criança. Os pais com melhores habilidades acreditam que para o melhor desenvolvimento de seus filhos é necessário dedicar maior quantidade de tempo e renda para cada uma das crianças. Por isso esse pais têm o número de filhos reduzido. Essa tabela mostra a relação positiva entre os anos de atraso escolar e o número de irmãos, quanto 
Tabela 3: Características do Atraso Escolar

\begin{tabular}{|c|c|c|c|c|}
\hline Anos de Atraso Escolar & $\begin{array}{l}\text { N.Médio } \\
\text { irmãos }\end{array}$ & $\begin{array}{c}\text { Educação } \\
\text { média da mãe* }\end{array}$ & $\begin{array}{c}\text { Educação } \\
\text { média do pai* }\end{array}$ & $\begin{array}{c}\text { Educação } \\
\text { média da avó* }\end{array}$ \\
\hline 0 & $\begin{array}{c}2,42 \\
(2,04)\end{array}$ & $\begin{array}{c}4,33 \\
(2,34)\end{array}$ & $\begin{array}{c}4,25 \\
(2,41)\end{array}$ & $\begin{array}{c}2,20 \\
(1,58)\end{array}$ \\
\hline 1 & $\begin{array}{c}3,39 \\
(2,45)\end{array}$ & $\begin{array}{c}3,14 \\
(1,91)\end{array}$ & $\begin{array}{c}3,03 \\
(1,90)\end{array}$ & $\begin{array}{c}1,69 \\
(1,16)\end{array}$ \\
\hline 2 & $\begin{array}{c}3,90 \\
(2,60)\end{array}$ & $\begin{array}{c}2,79 \\
(1,72)\end{array}$ & $\begin{array}{c}2,64 \\
(1,71)\end{array}$ & $\begin{array}{c}1,55 \\
(1,01)\end{array}$ \\
\hline 3 & $\begin{array}{c}4,24 \\
(2,66)\end{array}$ & $\begin{array}{c}2,54 \\
(1,61)\end{array}$ & $\begin{array}{c}2,41 \\
(1,63)\end{array}$ & $\begin{array}{c}1,48 \\
(0,90)\end{array}$ \\
\hline 4 & $\begin{array}{c}4,68 \\
(2,76)\end{array}$ & $\begin{array}{c}2,27 \\
(1,48)\end{array}$ & $\begin{array}{c}2,16 \\
(1,47)\end{array}$ & $\begin{array}{c}1,38 \\
(0,76)\end{array}$ \\
\hline 5 & $\begin{array}{c}4,95 \\
(2,80)\end{array}$ & $\begin{array}{c}2,08 \\
(1,37)\end{array}$ & $\begin{array}{c}1,97 \\
(1,37)\end{array}$ & $\begin{array}{c}1,34 \\
(0,74)\end{array}$ \\
\hline 6 & $\begin{array}{c}5,11 \\
(2,81)\end{array}$ & $\begin{array}{c}1,95 \\
(1,40)\end{array}$ & $\begin{array}{c}1,90 \\
(1,42)\end{array}$ & $\begin{array}{c}1,31 \\
(0,79)\end{array}$ \\
\hline 7 & $\begin{array}{c}5,21 \\
(2,88)\end{array}$ & $\begin{array}{c}2,07 \\
(1,62)\end{array}$ & $\begin{array}{c}2,05 \\
(1,66)\end{array}$ & $\begin{array}{c}1,39 \\
(0,97)\end{array}$ \\
\hline 8 & $\begin{array}{c}5,22 \\
(2,91)\end{array}$ & $\begin{array}{c}1,91 \\
(1,49)\end{array}$ & $\begin{array}{c}1,87 \\
(1,60)\end{array}$ & $\begin{array}{c}1,35 \\
(0,83)\end{array}$ \\
\hline 9 & $\begin{array}{c}5,34 \\
(3,02)\end{array}$ & $\begin{array}{c}2,02 \\
(1,67)\end{array}$ & $\begin{array}{l}1,79 \\
(1,5)\end{array}$ & $\begin{array}{c}1,29 \\
(0,71)\end{array}$ \\
\hline Total & $\begin{array}{c}3,12 \\
(2,48) \\
\end{array}$ & $\begin{array}{c}3,3 \\
(2,26)\end{array}$ & $\begin{array}{c}3,55 \\
(2,32)\end{array}$ & $\begin{array}{c}1,92 \\
(1,41)\end{array}$ \\
\hline
\end{tabular}

*por nível de escolaridade

() - valor do desvio-padrão

Fonte:PNAD 1996

maior os anos de atraso escolar maior é a quantidade de irmãos na família. A escala do desempenho escolar das crianças apresenta melhores resultados para as categorias com nível maior de escolaridade média de seus familiares.

Entre os resultados apresentados na tabela (3), as crianças que estão adequadas as suas séries têm pais com nível médio de escolaridade em nível fundamental. Os dados de escolaridade das mães também seguem os resultados apresentados pelos pais, mesmo que não homogêneos no critério do sentido do efeito para as últimas categorias. Nas categorias anos de atraso 7 e 9 os valores para nível médio da educação das mães não acompanham a tendência decrescente, mas seus valores continuam sendo próximos. Esse fato decorre 
da diminuição do número absoluto das observações nessas categorias

Tabela 4: Características sociais médias condicionada ao nível de escolaridade da mãe

\begin{tabular}{lccccc}
\hline Formação escolar da mãe & $\begin{array}{c}\text { Renda } \\
\text { Familiar Média }\end{array}$ & $\begin{array}{c}\text { N. médio } \\
\text { de filhos }\end{array}$ & $\begin{array}{c}\text { Atraso } \\
\text { escolar médio }\end{array}$ & $\begin{array}{c}\text { Educação } \\
\text { média do pai }\end{array}$ & $\begin{array}{c}\text { Horas traba } \\
\text {-lhadas da mãe** }\end{array}$ \\
\hline sem nenhuma escolaridade & 348,07 & 6,06 & 2,26 & 1,73 & 1,41 \\
& $(377,03)$ & $(3,54)$ & $(2,29)$ & $(1,17)$ & $(1,75)$ \\
ensino básico incompleto & 441,35 & 4,48 & 1,56 & 2,33 & 1,12 \\
& $(569,82)$ & $(3,12)$ & $(1,92)$ & $(1,32)$ & $(1,60)$ \\
ensino básico completo & 581,71 & 3,33 & 1,03 & 3,05 & 0,94 \\
& $(630,95)$ & $(2,57)$ & $(1,58)$ & $(1,55)$ & $(1,54)$ \\
ensino fundamental incompleto & 637,55 & 2,72 & 0,81 & 3,80 & 0,64 \\
& $(785,79)$ & $(2,24)$ & $(1,42)$ & $(1,72)$ & $(1,33)$ \\
ensino fundamental completo & 880,54 & 2,32 & 0,63 & 4,60 & 0,50 \\
& $(1022,15)$ & $(1,98)$ & $(1,28)$ & $(1,95)$ & $(1,17)$ \\
ensino médio incompleto & 938,16 & 2,02 & 0,47 & 5,14 & 0,41 \\
& $(1034,07)$ & $(1,84)$ & $(1,07)$ & $(1,95)$ & $(1,07)$ \\
ensino médio completo & 1468,56 & 1,91 & 0,35 & 5,96 & 0,29 \\
ensino superior incompleto & $(1696,48)$ & $(1,66)$ & $(1,00)$ & $(2,19)$ & $(0,88)$ \\
ensino superior completo ou mais & 2104,75 & 1,59 & 0,20 & 6,90 & 0,19 \\
& $(1916,21)$ & $(1,21)$ & $(0,79)$ & $(2,01)$ & $(0,71)$ \\
& 3388,34 & 1,53 & 0,20 & 7,72 & 0,13 \\
Total & $(3499,79)$ & $(1,25)$ & $(0,84)$ & $(1,82)$ & $(0,57)$ \\
\hline
\end{tabular}

** por categoria

( ) - valor do desvio-padrão

Fonte:PNAD 1996

A tabela (4) apresenta as relações entre os níveis de escolaridade da mãe e as variáveis renda média familiar, número médio de filhos, e a categoria que representa as horas por elas trabalhadas. O nível de escolaridade dos pais e das mães é semelhante em cada categoria, ou seja, quando a mãe apresenta nenhum grau de escolaridade em média o marido também se encontra nesse no mesmo nível e assim por diante. Ao entender que a escolaridade de cada responsável pela família é semelhante, ambos são responsáveis por contribuírem no mesmo sentido para a renda familiar e para os cuidados da criança, intensificando o fator positivo da escolaridade dos pais no processo de desenvolvimento da criança. A renda média familiar quando a mãe não possui nenhuma escolaridade é $R \$ 348,07$ e atinge a média de $R \$ 3388,34$ quase dez vezes mais quando a mãe apresenta nível superior completo ou mais. A partir desses dados podemos verificar a importância da educação dos pais na formação da renda familiar. Essa restrição financeira é um dos principais fatores que compõem o investimento privado em educação, ou seja é o fator que 
limita o investimento em capital humano em países em desenvolvimento.

O número médio de filhos para as mães com nenhum nível de escolaridade é 6,06, esse número cai para 1,53 para as mães com nível superior completo ou mais. Esses dados mostram que as mães com maior escolaridade têm menor quantidade de filhos pois atrasam o início da maternidade e assim garantem condições de estudar por um período maior. O fato de possuir maior nível de escolaridade permite a essa mãe compreende melhor os cuidados necessários para o cuidado de um filho e assim restringir o número total de filhos para fornecer melhores condições de tempo disponível para o cuidado e maior parcela da renda.

Os anos de atraso escolar médio apresentado pelos filhos de mães com nenhum nível de escolaridade é 2,26 e esse valor se reduz para menos de um $(0,81)$ para as mães com nível fundamental incompleto. A relação entre o nível de escolaridade da mãe e os anos de atraso escolar médio da criança é negativa, quanto maior o nível educacional da mãe menor é a média de anos de atraso escolar apresentado pelos filhos.

\subsection{Resultados das estimações}

\subsubsection{O Modelo Linear Simples}

O modelo linear é composto pelas seguintes variáveis:

- variável dependente: anos de atraso escolar $\left(y_{1}\right)$,

- variáveis explicativas exógenas $\left(z_{1}\right)$ : raça negra, região Norte, região Nordeste, região Centro Oeste, região Sul e região Sudeste, área urbana, gênero masculino, idade da criança, horas trabalhadas da mãe,

- variável explicativa endógena $\left(y_{2}\right)$ : renda familiar, nível de escolaridade da mãe e do pai.

A estimação por MQO com a presença de uma variável endógena resulta em estimadores viesados e inconsistentes. O modelo linear por MQO ilustra o sentido dos efeitos 
de cada variável.

$$
y_{1}=z_{1} \delta_{1}+\alpha_{1} y_{2}+u_{1}
$$

O modelo estimado por método de mínimos quadrados ordinários é apresentado na tabela (5):

Tabela 5: Estimação do atraso escolar - MQO

\begin{tabular}{|c|c|c|c|c|}
\hline Anos de atraso escolar & Coeficientes & Erro Padrão & $t$ & $P>t$ \\
\hline idade da criança & 0,248 & 0,002 & 136,87 & 0,000 \\
\hline renda familiarᄎ & $-0,003$ & 0,004 & $-8,58$ & 0,000 \\
\hline horas trabalhadas da mãe $e^{* *}$ & 0,058 & 0,004 & 14,04 & 0,000 \\
\hline nordeste & 0,515 & 0,014 & 36,15 & 0,000 \\
\hline sul & $-0,059$ & 0,017 & $-3,53$ & 0,000 \\
\hline centro oeste & 0,144 & 0,021 & 7,02 & 0,000 \\
\hline norte & 0,309 & 0,022 & 14,00 & 0,000 \\
\hline área urbana & $-0,339$ & 0,014 & $-24,15$ & 0,000 \\
\hline gênero masculino & 0,315 & 0,011 & 28,85 & 0,000 \\
\hline raça negra & 0,159 & 0,012 & 12,78 & 0,000 \\
\hline educação da mãe* & $-0,090$ & 0,004 & $-24,72$ & 0,000 \\
\hline educação do pai* & $-0,051$ & 0,004 & $-14,27$ & 0,000 \\
\hline número de irmãos & 0,078 & 0,003 & 28,94 & 0,000 \\
\hline intercepto & $-1,882$ & 0,030 & $-62,93$ & 0,000 \\
\hline Prob $>F=0,000$ & & \multicolumn{3}{|c|}{$R^{2}=0,604$} \\
\hline
\end{tabular}

A partir da tabela(5) verifica-se que as variáveis renda familiar, educação da mãe, educação do pai, urbano e região sul apresentam efeitos negativos para o atraso escolar. Quanto maior a renda familiar do indivíduo menor é a chance da criança apresentar atraso escolar. A educação do pai e da mãe, como enfatizados anteriormente, também são responsáveis por diminuir os anos de atraso escolar. As crianças e jovens que vivem nas áreas urbanas apresentam resultado melhor quando comparada as outras, por isso, seu sinal é negativo para o atraso escolar. Ao comparar a região Sudeste com as demais, verificamos que o atraso escolar diminui apenas em relação a região Sul, as demais quando comparadas com a região Sudeste apresentam piores níveis de atraso escolar.

A variável número de irmãos indica que quanto maior a quantidade de irmãos, menor é o tempo de dedicação dos pais e a renda per capita disponível para cada criança. Por esse fato, a variável afeta positivamente os anos de atraso escolar. As horas trabalhadas 
da mãe afetam o atraso escolar de forma positiva indicando que quanto maior o categoria de horas que a mãe trabalha menor é o tempo dedicado no cuidado dos filhos, o que afeta de forma direta a formação de capital humano das crianças.

Meninos têm mais atraso escolar quando comparado às meninas. O custo de oportunidade do menino em continuar os estudos é maior em relação à menina devido às chances no mercado de trabalho. A raça negra quando comparada aos brancos e aos amarelos apresenta maior freqüência de indivíduos com atraso escolar.

Acredita-se que as variáveis nível educacional da mãe, do pai e a renda familiar são endógenas no modelo de anos de atraso escolar. O nível educacional da mãe direciona o investimento do capital humano do filho e também no atraso escolar do filho. Mães mais educadas, em geral, representam maior acúmulo de capital humano.

\subsubsection{Teste de endogeneidade}

De acordo com a discussão anterior, testamos a endogeneidade de três variáveis, quais sejam, o nível de escolaridade da mãe, o nível de escolaridade do pai e a renda familiar. As variáveis utilizadas para a construção desse teste foram as seguintes:

- variável dependente $\left(y_{1}\right)$ : anos de atraso escolar

- variáveis exógenas incluídas $\left(z_{1}\right)$ : raça negra, região Norte, região Nordeste, região Sul, região Sudeste e região Centro-Oeste, categoria das horas trabalhadas da mãe, gênero masculino, idade da criança e área urbana.

- variáveis endógenas $\left(y_{2}\right)$ : renda familiar, nível de escolaridade da mãe e do pai

- variáveis exógenas excluídas $\left(z-z_{1}\right)$ : nível de escolaridade dos avós e avôs materno e paterno.

Seguindo Wooldridge (2002), no primeiro estágio o objetivo é estimar o resíduo da equação de cada uma das variáveis endógenas $\left(y_{2}\right)$ a partir de todas as variáveis exógenas representadas por z. No segundo estágio, estima-se o ano de atraso escolar incluindo o resíduo estimado e as outras variáveis explicativas $\left(z_{1}\right)$. Nos três casos constatou-se a 
significância dos resíduos, o que sugere a existência de uma variável não observável no resíduo relacionada com as variáveis incluídas no modelo. Em outras palavras, encontramos evidências de que há endogeneidade.

As tabelas (6) a (11) apresentam os modelos estimados no primeiro estágio e segundo estágio, que representam o resultado.

O resultado encontrado no segundo estágio para a educação da mãe, Tabela (7), significa que pode existir alguma variável não observada no modelo que está relacionada tanto com a educação dos pais quanto à melhoria do desempenho da criança, possivelmente associada à "habilidade" ou "capacidadade" dos pais. Como mencionado anteriormente, pessoas com mais habilidade tendem a avançar mais nos estudos pois custo dos anos adicionais na escola é menor quanto maior a habilidade formada no período anterior.

Tabela 6: Estimação da variável e do resíduo da educação da mãe - Primeiro estágio

\begin{tabular}{|c|c|c|c|c|}
\hline Educação da mãe* & Coeficientes & Erro Padrão & $t$ & $P>t$ \\
\hline idade da criança & 0,017 & 0,003 & 6,06 & 0,000 \\
\hline horas trabalhadas da mãe** & $-0,127$ & 0,007 & $-19,39$ & 0,000 \\
\hline nordeste & 0,123 & 0,023 & 5,36 & 0,000 \\
\hline sul & $-0,135$ & 0,026 & $-5,28$ & 0,000 \\
\hline centro oeste & 0,180 & 0,033 & 5,51 & 0,000 \\
\hline norte & 0,180 & 0,038 & 4,72 & 0,000 \\
\hline área urbana & 0,615 & 0,022 & 28,17 & 0,000 \\
\hline gênero masculino & 0,026 & 0,017 & 1,49 & 0,136 \\
\hline raça negra & $-0,389$ & 0,020 & $-19,51$ & 0,000 \\
\hline número de irmãos & $-0,209$ & 0,004 & $-50,40$ & 0,000 \\
\hline educação da avó materna* & 0,340 & 0,009 & 39,28 & 0,000 \\
\hline educação do avô materno* & 0,259 & 0,008 & 32,29 & 0,000 \\
\hline educação da avó paterna* & 0,209 & 0,009 & 23,15 & 0,000 \\
\hline educação do avô paterno & 0,142 & 0,008 & 17,22 & 0,000 \\
\hline intercepto & 2,046 & 0,046 & 44,53 & 0,000 \\
\hline Prob $>F=0,000$ & & \multicolumn{3}{|c|}{$R^{2}=0,4995$} \\
\hline
\end{tabular}

A equação utilizada para estimação do resíduo para o teste de endogeneidade da educação do pai é representada por (4.11) e os resultados obtidos são apresentados na tabela (8). A regressão do segundo estágio, tabela (9), mostra que o termo do resíduo também é significante e, portanto, a variável educação dos pais é endógena e deve ser tratada no intuito de fornecer estimações consistentes. 
Tabela 7: Teste de endogeneidade - para a variável educação da mãe

\begin{tabular}{|c|c|c|c|c|}
\hline Anos de atraso escolar & Coeficientes & Erro Padrão & $t$ & $P>t$ \\
\hline resíduo educação da mãe & $-0,045$ & 0,008 & $-5,53$ & 0,000 \\
\hline idade da criança & 0,235 & 0,002 & 102,98 & 0,000 \\
\hline 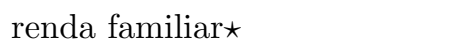 & $-0,0369$ & 0,005 & $-7,05$ & 0,000 \\
\hline horas trabalhadas da mãe** & 0,071 & 0,005 & 13,35 & 0,000 \\
\hline nordeste & 0,540 & 0,018 & 29,64 & 0,000 \\
\hline sul & $-0,034$ & 0,020 & $-1,68$ & 0,093 \\
\hline centro-oeste & 0,148 & 0,026 & 5,74 & 0,000 \\
\hline norte & 0,313 & 0,030 & 10,43 & 0,000 \\
\hline área urbana & $-0,357$ & 0,018 & $-19,54$ & 0,000 \\
\hline gênero masculino & 0,287 & 0,014 & 20,93 & 0,000 \\
\hline raça negra & 0,187 & 0,016 & 11,39 & 0,000 \\
\hline número de irmãos & 0,094 & 0,004 & 24,59 & 0,000 \\
\hline educação da mãe* & $-0,050$ & 0,005 & $-10,85$ & 0,000 \\
\hline educação do pai* & $-0,046$ & 0,008 & $-5,59$ & 0,000 \\
\hline intercepto & $-1,950$ & 0,044 & $-44,35$ & 0,000 \\
\hline Prob $>F=0,000$ & & & $R^{2}=0,402$ & \\
\hline
\end{tabular}

A variável renda familiar também deve ser testada para endogeneidade. Pais com melhores salários indicam melhor produtividade, que tiveram maior acúmulo de capital humano e portanto, mais habilidade. A variável habilidade também impacta na formação de capital humano na criança, como visto no modelo teórico. Desta forma, o teste foi feito para a renda familiar, da mesma maneira que aplicada para a educação da mãe e do pai. Os resultados obtidos são apresentados nas tabelas 10 e 11.

Analisando a tabela 10, constatamos que o resíduo da renda familiar também é significativo na regressão de atraso escolar, confirmando a intuição sobre a natureza endógena da variável renda.

Nesse estudo, outros testes foram aplicados são eles: de heteroscedasticidade do erro, da endogeneidade conjunta e o teste de sobreidentificação. É importante detectar a heteroscedasticidade do erro para o uso de correções na aplicação dos testes. Para isso, utilizamos o teste de Koenker/White, que tem como um dos seus diferenciais a não necessidade da hipótese de normalidade do erro. A hipótese de homoscedasticidade do termo aleatório é rejeitada, deve-se considerar, portanto, que existe heteroscedasticidade para aplicação dos testes. 
Tabela 8: Estimação da variável e do resíduo da educação do pai - Primeiro estágio

\begin{tabular}{|c|c|c|c|c|}
\hline Educação do pai* & Coeficientes & Erro Padrão & $t$ & $\overline{P>t}$ \\
\hline idade da criança & 0,015 & 0,003 & 5,30 & 0,000 \\
\hline horas trabalhadas da mãe** & $-0,141$ & 0,007 & $-21,22$ & 0,000 \\
\hline nordeste & $-0,166$ & 0,023 & $-7,16$ & 0,000 \\
\hline sul & $-0,078$ & 0,026 & $-3,03$ & 0,002 \\
\hline centro oeste & 0,031 & 0,033 & 0,95 & 0,344 \\
\hline norte & $-0,086$ & 0,038 & $-2,25$ & 0,024 \\
\hline área urbana & 0,777 & 0,022 & 35,17 & 0,000 \\
\hline gênero masculino & 0,034 & 0,018 & 1,93 & 0,054 \\
\hline raça negra & $-0,430$ & 0,020 & $-21,33$ & 0,000 \\
\hline número de irmãos & $-0,162$ & 0,004 & $-38,72$ & 0,000 \\
\hline educação da avó materna* & 0,207 & 0,009 & 23,66 & 0,000 \\
\hline educação do avô materno* & 0,211 & 0,009 & 26,00 & 0,000 \\
\hline educação da avó paterna* & 0,299 & 0,009 & 32,89 & 0,000 \\
\hline educação do avô paterno* & 0,302 & 0,008 & 36,40 & 0,000 \\
\hline intercepto & 1,723 & 0,046 & 37,13 & 0,000 \\
\hline Prob $>F=0,000$ & & \multicolumn{3}{|c|}{$R^{2}=0,5235$} \\
\hline
\end{tabular}

O teste de endogeneidade conjunta, proposto originalmente por Sargan, considera uma combinação linear das variáveis endógenas e testa a ortogonalidade desta combinação com o erro. O p-valor associado ao teste $\mathrm{C}$ (robusto à heteroscedasticidade) é muito próximo de zero, levando à rejeição da hipótese nula . Desta forma, confirma-se mais uma evidência de que há endogeneidade em pelo menos uma das variáveis consideradas (educação da mãe, educação do pai ou renda familiar).

Como pretendemos utilizar instrumentos para contornar o problema de endogeneidade apontado acima, é conveniente aplicar um teste de sobre-identificação. Este tipo de teste é importante neste contexto pois valida, de certa forma, os instrumentos utilizados. A idéia geral deste tipo de teste é verificar se a combinação linear dos instrumentos é ortogonal à variável endógena. O resultado obtido foi a rejeição da hipótese nula de não ortogonalidade dos instrumentos ao nível de 8\%. Ainda que o nível de significância necessário para validar os instrumentos é relativamente alto nesse caso, é possível argumentar de que há pelo menos alguma evidência de que os instrumentos são razoáveis. 
Tabela 9: Teste de endogeneidade - para a variável educação do pai

\begin{tabular}{|c|c|c|c|c|}
\hline Anos de atraso escolar & Coeficientes & Erro Padrão & $t$ & $P>t$ \\
\hline resíduo educação do pai & $-0,045$ & 0,008 & $-5,92$ & 0,000 \\
\hline idade da criança & 0,235 & 0,002 & 103,05 & 0,000 \\
\hline renda familiarᄎ & $-0,003$ & $0,005,23$ & $-7,14$ & 0,000 \\
\hline horas trabalhadas da mãe** & 0,072 & 0,005 & 13,45 & 0,000 \\
\hline nordeste & 0,553 & 0,018 & 30,35 & 0,000 \\
\hline sul & $-0,036$ & 0,020 & $-1,79$ & 0,073 \\
\hline centro-oeste & 0,156 & 0,026 & 6,06 & 0,000 \\
\hline norte & 0,325 & 0,030 & 10,85 & 0,000 \\
\hline área urbana & $-0,364$ & 0,019 & $-19,66$ & 0,000 \\
\hline gênero masculino & 0,287 & 0,014 & 20,89 & 0,000 \\
\hline raça negra & 0,188 & 0,016 & 11,50 & 0,000 \\
\hline número de irmãos & 0,092 & 0,004 & 25,27 & 0,000 \\
\hline educação do pai* & $-0,007$ & 0,008 & $-0,94$ & 0,345 \\
\hline educação da mãe* & $-0,091$ & 0,005 & $-19,35$ & 0,000 \\
\hline intercepto & $-1,937$ & 0,042 & $-45,97$ & 0,000 \\
\hline
\end{tabular}

$\star$ renda familiar em milhares de Reais * por nível de escolaridade

** por categoria

\subsubsection{O Modelo com dados em contagem}

A tabela (13) apresenta os resultados da estimação pelo modelo de Poisson. Esse modelo, como visto anteriormente, é restrito pois a natureza da distribuição de Poisson considera que a variância e a média são iguais. Após a estimação, foi feito o teste $\chi_{2}$ para overdispersion (variância excede a média). A hipótese nula foi rejeitada, identificando que existe overdispersion, e portanto o modelo de Poisson não é adequado para representar esses dados de atraso escolar.

A figura (5.2.3) compara as distribuições de poisson, binomial negativa e a da amostra. Nesta figura é possível verificar visualmente que a amostra provavelmente não segue a distribuição de Poisson. Aparentemente, a distribuição binomial negativa representa de forma mais adequada a distribuição da amostra.

A tabela (14) compara as três estimações descritas nesse estudo. A primeira coluna representa a estimação por mínimos quadrados em dois estágios. Nesse modelo, assumese que a variável renda, educação da mãe e do pai são endógenas e por isso são feitas estimações dessas variáveis no primeiro estágio. No segundo estágio, estima-se o atraso escolar em relação as variáveis exógenas incluídas e as endógenas estimadas. O resul- 
Tabela 10: Estimação da variável e do resíduo da renda familiar - Primeiro estágio

\begin{tabular}{lcccc}
\hline Renda familiar & Coeficientes & Erro Padrão & $t$ & $P>t$ \\
\hline idade da criança & 44,104 & 2,376 & 18,56 & 0,000 \\
horas trabalhadas da mãe* & $-6,248$ & 5,431 & $-1,15$ & 0,250 \\
nordeste & $-98,111$ & 18,999 & $-5,16$ & 0,000 \\
sul & $-132,438$ & 21,034 & $-6,30$ & 0,000 \\
centro oeste & 131,384 & 26,873 & 4,89 & 0,000 \\
norte & $-134,265$ & 31,213 & $-4,30$ & 0,000 \\
área urbana & 241,305 & 18,090 & 13,34 & 0,000 \\
gênero masculino & 13,668 & 14,363 & 0,95 & 0,341 \\
raça negra & $-276,476$ & 16,469 & $-16,79$ & 0,000 \\
número de irmãos & $-6,955$ & 3,441 & $-2,02$ & 0,043 \\
educação da avó materna* & 147,487 & 7,163 & 20,59 & 0,000 \\
educação do avô materno* & 152,664 & 6,649 & 22,96 & 0,000 \\
educação da avó materna* & 127,636 & 7,484 & 17,06 & 0,000 \\
educação do avô paterno* & 145,857 & 6,828 & 21,36 & 0,000 \\
intercepto & $-705,565$ & 38,010 & $-18,56$ & 0,000 \\
\hline Prob $>F$ = 0,000 & \multicolumn{4}{c}{$R^{2}=0,2665$} \\
\hline *por nível de escolaridade & \multicolumn{5}{|}{} \\
** por categoria & & &
\end{tabular}

tado encontrado mostra que a renda familiar, a educação dos pais e região sul são não significantes.

A estimação pela função de quase máxima verossimilhança apresenta dados significativos para as variáveis endógenas tratadas. As variáveis exógenas, quando comparamos entre MQ2E e QML2E apresentam magnitude semelhantes, mas as variáveis endógenas tratadas tiveram resultados bastante diferentes. O resultado da estimação da educação da mãe em MQ2E apresentou impacto de -0,169 com significância ao nível de 1\% no atraso escolar, enquanto em QML2E o impacto foi calculado em -0,535. A diferença entre as magnitudes atinge valores três vezes maiores. O modelo de QML2E é mais adequado pois além de tratar a endogeneidade, respeita a natureza de contagem dos dados. O método de quase verossimilhança apresenta estimações dos parâmetros consistentes sob hipótese fraca de exogeneidade das variáveis explicativas. Essa hipótese pode ser assumida depois do tratamento das variáveis endógenas no primeiro estágio. A variável educação do pais em QML2E também apresenta efeito negativo no atraso escolar mas a magnitude do impacto quando comparada com os resultados da mãe, chega a ser quase a metade. Assim, a educação do pais impactam em -0,268 com nível de significância em 1\%. As mães têm maior influência na educação do filho, no processo de formação de capital humano, 
Tabela 11: Teste de endogeneidade - para a variável renda familiar

\begin{tabular}{|c|c|c|c|c|}
\hline Anos de atraso escolar & Coeficientes & Erro Padrão & $t$ & $P>t$ \\
\hline resíduo da renda familiar & $-0,07,97$ & 0,001 & $-5,87$ & 0,000 \\
\hline idade da criança & 0,232 & 0,002 & 99,07 & 0,000 \\
\hline renda familiar* & 0,042 & 0,0135 & 3,14 & 0,002 \\
\hline horas trabalhadas da mãe** & 0,066 & 0,005 & 12,66 & 0,000 \\
\hline nordeste & 0,553 & 0,018 & 30,37 & 0,000 \\
\hline sul & $-0,029$ & 0,020 & $-1,45$ & 0,146 \\
\hline centro-oeste & 0,146 & 0,026 & 5,68 & 0,000 \\
\hline norte & 0,332 & 0,030 & 11,08 & 0,000 \\
\hline área urbana & $-0,348$ & 0,018 & $-19,49$ & 0,000 \\
\hline gênero masculino & 0,288 & 0,014 & 20,93 & 0,000 \\
\hline raça negra & 0,191 & 0,017 & 11,57 & 0,000 \\
\hline número de irmãos & 0,085 & 0,003 & 24,89 & 0,000 \\
\hline educação do pai* & $-0,052$ & 0,005 & $-11,01$ & 0,000 \\
\hline educação da mãe* & $-0,091$ & 0,005 & $-19,37$ & 0,000 \\
\hline intercepto & $-1,803$ & 0,038 & $-48,07$ & 0,000 \\
\hline
\end{tabular}

$\star$ renda familiar em milhares de Reais * por nível de escolaridade

** por categoria

Tabela 12: Teste de endogeneidade conjunta, heteroscedasticidade e sobreidentificação

\begin{tabular}{|c|c|}
\hline Teste para heteroscedasticidade & \\
\hline Ho: Disturbância Homoscedastica & \\
\hline estatística teste Koenker/White $=98,379$ & $p-$ valor $=0,0000$ \\
\hline Teste endogeneidade conjunta com co & eteroscedasticidade - Teste C \\
\hline Ho: Combinação linear das variáveis endóg & nais ao modelo \\
\hline estatística teste Sargan $=383,130$ & $p-$ valor $=0,0000$ \\
\hline Teste instrumentos sobreidentificado & \\
\hline Ho: Combinação linear dos instrumentos & variável endógena \\
\hline estatística teste J-Hansen $=2,960$ & $p-$ valor $=0,0853$ \\
\hline
\end{tabular}

mesmo que ambos sejam responsáveis pelo efeito negativo.

Esses resultados estão de acordo com a literatura que mostra o impacto negativo da educação dos pais no atraso escolar. Desta forma, mostra-se que pais com maiores níveis educacionais são aqueles que mantém maiores condições de investimento em capital humano nos filhos.

De forma diferente das conclusões da literatura dessa área, a renda familiar em QML2E, apresentou impacto positivo na educação familiar, pessoas com maior renda familiar apresentam na média, maior nível de atraso escolar.

O modelo Hurdle utilizou o método de estimação por Máxima verossimilhança. A função base considerada foi a binomial negativa, conclusão obtida a partir do gráfico 
Tabela 13: Modelo de Poisson

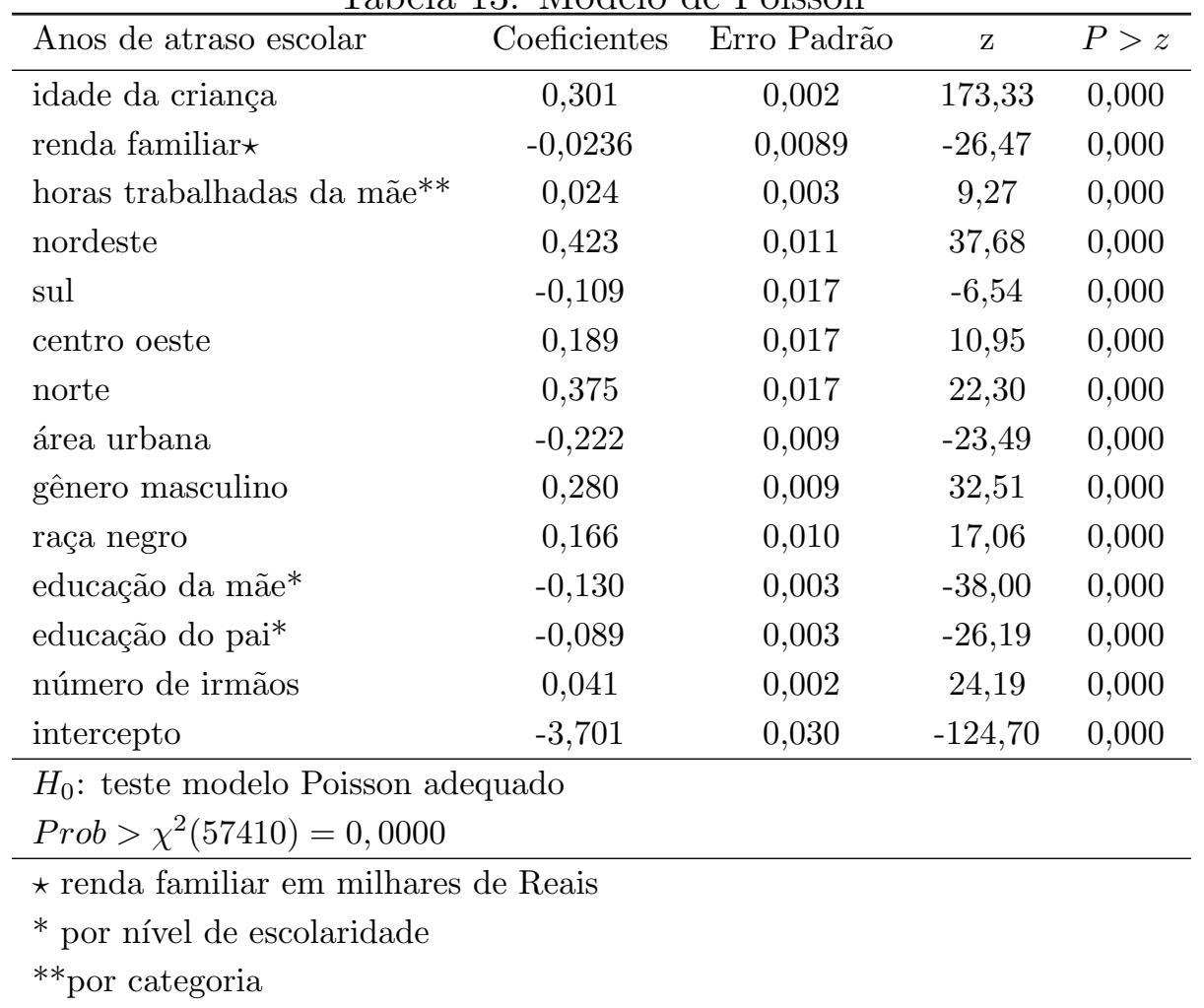

(4.30). O gráfico(??) apresentou uma grande quantidade de zeros na variável anos de atraso escolar mostrando que apenas a função binomial negativa não seria capaz de especificar corretamente esse modelo. Entretanto, mesmo que a especificação seja feita de forma adequada, a estimação por máxima verossimilhança apresenta parâmetros inconsistentes na presença de endogeneidade. O resultado apresentado é interessante pois mostra a diferença na magnitude entre os modelos especificados de forma diferente. 


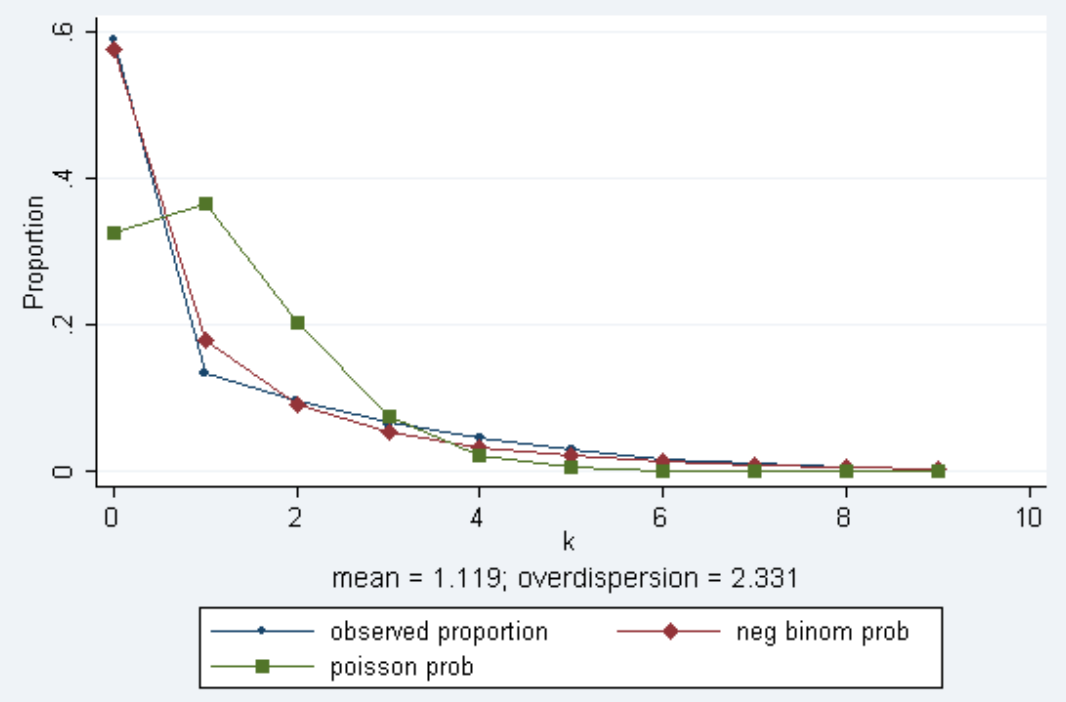

Figura 6: Comparação entre as distribuição binomial negativa, poisson e dos dados 
Tabela 14: MQ2E X QML X ML

\begin{tabular}{|c|c|c|c|}
\hline Anos de atraso escolar & MQ2E & QML2E & $\mathrm{ML}$ \\
\hline idade da criança & $\begin{array}{c}0,227 \\
(0,008)\end{array}$ & $\begin{array}{c}0,305 \\
(0,012)\end{array}$ & $\begin{array}{c}0,155 \\
(0,002)\end{array}$ \\
\hline horas trabalhadas da mãe** & $\begin{array}{l}0,055^{*} \\
(0,017)\end{array}$ & $\begin{array}{c}-0,056^{* *} \\
(0,025)\end{array}$ & $\begin{array}{c}0,017 \\
(0,002)\end{array}$ \\
\hline nordeste & $\begin{array}{c}0,577 \\
(0,027)\end{array}$ & $\begin{array}{c}0,657 \\
(0,035)\end{array}$ & $\begin{array}{c}0,231 \\
(0,010)\end{array}$ \\
\hline sul & & & $\begin{array}{c}-0,032^{\text {** }} \\
(0,016)\end{array}$ \\
\hline centro-oeste & $\begin{array}{c}0,139 \\
(0,029)\end{array}$ & $\begin{array}{c}0,208 \\
(0,038)\end{array}$ & $\begin{array}{c}0,056 \\
(0,016)\end{array}$ \\
\hline norte & $\begin{array}{c}0,372 \\
(0,047)\end{array}$ & $\begin{array}{c}0,69 \\
(0,062)\end{array}$ & $\begin{array}{c}0,151 \\
(0,015)\end{array}$ \\
\hline área urbana & $\begin{array}{l}-0,340 \\
(0,042)\end{array}$ & & $\begin{array}{l}-0,146 \\
(0,008)\end{array}$ \\
\hline gênero masculino & $\begin{array}{c}0,288 \\
(0,014)\end{array}$ & $\begin{array}{c}0,298 \\
(0,015)\end{array}$ & $\begin{array}{c}0,125 \\
(0,008)\end{array}$ \\
\hline raça negra & $\begin{array}{c}0,196 \\
(0,018)\end{array}$ & $\begin{array}{c}0,192 \\
(0,021)\end{array}$ & $\begin{array}{c}0,062 \\
(0,008)\end{array}$ \\
\hline número de irmãos & $\begin{array}{l}0,066^{*} \\
(0,023)\end{array}$ & $\begin{array}{c}-0,061^{* *} \\
(0,034)\end{array}$ & \\
\hline educação das mães estimada* & $\begin{array}{c}-0,169^{*} \\
(0,066)\end{array}$ & $\begin{array}{l}-0,535 \\
(0,099)\end{array}$ & $\begin{array}{l}-0,055 \\
(0,003)\end{array}$ \\
\hline educação dos pais estimados* & & $\begin{array}{l}-0,268^{*} \\
(0,107)\end{array}$ & $\begin{array}{l}-0,027 \\
(0,003)\end{array}$ \\
\hline renda familiar estimada & & $\begin{array}{c}0,826 * * \\
(0,329)\end{array}$ & $\begin{array}{l}-0,040 \\
(0,001)\end{array}$ \\
\hline intercepto & $\begin{array}{l}-1,498 \\
(0,403)\end{array}$ & $\begin{array}{l}-2,443 \\
(0,599)\end{array}$ & $\begin{array}{l}-1,153 \\
(0,023)\end{array}$ \\
\hline $\begin{array}{l}\text { *por nível de escolaridade } \\
\text { ** por categoria } \\
\text { () - desvio-padrão } \\
\text { - coeficiente significativo ao n } \\
\text { - para ML as variáveis endóg } \\
\text { - as variáveis omitidas são nã } \\
\text { - as estimações são signitican }\end{array}$ & $\begin{array}{l}(*) 19 \\
\text { s não } \\
\text { innific }\end{array}$ & $\begin{array}{l}*) \\
\text { *) } 5 \% \\
\text { estima }\end{array}$ & $10 \%$ \\
\hline
\end{tabular}




\section{Conclusão}

O estudo mostrou que existe diferenças na magnitude do impacto das características familiares no atraso escolar. Três métodos foram utilizados entre eles, apenas o método de quase verossilhança leva a estimadores consistentes e proporciona uma especificação correta dos dados de acordo com sua natureza de contagem. Nesse modelo, destaca-se que a magnitude do impacto negativo no atraso escolar em relação a educação do pai é menor que na mãe, sendo quase metade.

Foram utilizados os dados da PNAD 96 devido aos dados referentes à educação dos avós maternos e paternos. Esses dados foram essenciais para o tratamento da endogeneidade no modelo. Outra vantagem encontrada nesse banco de dados foi a representatividade do atraso escolar como uma medida de baixo nível de acúmulo de capital humano, já que as crianças em geral tinham acesso à escola.

Os testes para as variáveis potencialmente endógenas mostraram que as três, educação da mãe, do pai e a renda familiar apresentam seus resíduos correlacionados ao atraso escolar. Duas formas foram utilizadas para provar a endogeneidade. O primeiro teste verifica a significância do resíduo da variável endógena na regressão do atraso escolar. O segundo teste verifica a endogeneidade conjunta a partir da combinação linear das variáveis endógenas.

A educação da mãe, quando considerada exógena ao modelo de atraso escolar e calculada por MQO apresenta efeito em -0,090 no atraso escolar. Em QML2E, esse efeito chega a $-0,535$. Os efeitos nas estimações padrões são viesados.

Os efeitos encontrados em relação as variáveis educação da mãe e do pai utilizadas nos estudos estão de acordo com a literatura. A criança com maior potencial para estar 
com atraso escolar é aquela que possui maior número de irmãos, meninos, de raça negra moradores de regiões com menor infra-estrutura e menor educação dos pais. 


\section{Referências}

BARRO, R. J.; LEE, J. W. International data on educational attainment:updates and implications. Oxford Economic Papers, v. 53, n. 3, p. 541-63, 2001.

BAUM, C. F.; SCHAFFER, M.; STILLMAN, S. Instrumental variables and gmm estimation and testing. Woking Paper, Boston University, v. 545, 2003.

BECKER, G. S.; TOMES, N. An equilibrium theory of the distribution of income and intergenerational mobilit. Journal of Political Economic, v. 6, n. 87, p. 1153-89, 1979.

BECKER, G. S.; TOMES, N. Human capital and rise and fall of families. Journal of Labor Economics, v. 4, n. 3, parte 2, p. SI-39, 1986.

BEHRMAN, J. R.; POLLAK, R.; TAUBMAN, P. From parents to child. Intrahousehold allocations and intergerational relations in the United States. [S.l.]: Chicago, 1995.

BEHRMAN, J. R.; TAUBMAN, P. The intergeracional correlation between children's adults earning and their parents' income results from the michigan panel study of income dynamics. Review Income Wealth, v. 36, 1990.

BEHRMAN J. R.; WOLFE, B. L.; BLAU, D. Human Capital and Income Distribution in a Developing Country. [S.l.]: Institute for Research on Poverty, 1981.

BYRNES, D.; YAMAMOTO, k. Views on grade repetition. Journal of Research and Development in Education, v. 20, p. 14-20, 1989.

CAMERON, A. C.; TRIVEDI, P. K. Regression - based tests for overdispersion in the poisson model. Jounal of Econometrics, v. 46, p. 347-364, 1990.

CAMERON, S. V.; HECKMAN, J. J. Life cycle schooling and dynamic selection bias: Models and evidence for five cohort of american males. The Journal of Political Economy, v. 106, p. 262-333, 1998.

COLEMAN, J. S. Social capital in the creation of human capital. American Journal of Sociology, v. 94, p. S95-120, 1988.

CUNHA, F. et al. Interpreting the evidence on life cycle skill formation. Discussion Paper Series, v. 1675, 2005.

DAVIDSON, R.; MACKINNON, J. Econometric theory and methods. [S.l.]: Oxford University Press, 2004.

DUNCAN, O. D. A socioeconomic index for all occupations. [S.l.: s.n.], 1961.

DUNCAN, O. D.; HODGE, R. W. Education and occupational mobility: a regression analysis. American Jounal of Sociology, v. 68, p. 629-49, 1963. 
ERMISCH, J.; FRANCESCONI, M. Family matters: Impacts of family background on educational attainments. Economica, London School of Economics and Political Science, v. 68 , p. $137-56,2001$.

HANUSHEK, E. The trade-off between child quantity and quality. Journal of Political Economic, v. 100, n. 1, p. 84-117, 1992.

HANUSHEK, E. Economics of education. In: [S.l.]: International Encyclopedia of the social behavioral sciences, 2001. v. 6, p. $4200-4208$.

HAUSER, R. M.; FEATHERMAN, D. The process of stratification: Trends and analyses. [S.l.]: Academic Press, 1977.

HAUSER, R. M.; SEWELL, W. M. Familiy effects in simple models of education, occupational status, and earnings: findings from the wisconsin and kalamazoo studies. Journal of Labor Economic, v. 4, n. 4, p. S83-115, 1986.

HAUSMAN, J. A. Specification tests in econometrics. Econometrica, v. 46, p. 12511271, 1978.

HAUSMAN, J. A. Specification and estimation of simultaneous equations models. Z. griliches and m. d. intriligator. Amsterdam: North Holland, 1983.

HETHERINGTON, E. M.; CAMARA, K.; FEATHERMAN, D. L. Achievement and intellectual functioning of children in one-parent household. In: [S.1.]: Achievement and achievement motives : Psycological and sociological approach, 1983. p. $208-84$.

HOROWITZ, A.; SOUZA, A. P. A inequality in children academic achievement in single parents household: Evidences from brazil. 2005.

INHELDER, B.; PIAGET, J. The growth of logical thinking from childhood to adolescence. [S.l.]: Routledge \& Kegan Paul, 1958.

LEIBOWITZ, A. Home investments in children. Journal of Political Economic, v. 82, n. 2,II, p. S111-31, 1974.

LOURY, G. Intergenerational transfers and the distribution of earnings. Econometrica, v. 49 , p. $843-67,1981$.

MACAULEY, J. Stereotyping child welfare. Society, v. 13, p. 47-51, 1977.

MANKIW, G.; ROMER, D.; WEIL, D. The contribution to the empiric growth. The Quarterly Journal of Economics, v. 107, p. 407-37, 1992.

MAOZ, Y. D.; MOAV, O. Intergenerational mobility and the process of development. Economic Journal, v. 109, p. 677-97, 1999.

MCCUBBIN, H. I. Family stress, coping and social support: a decade review. Journal of Marriage and Familiy, v. 42, n. 4, p. 855-71, 1980.

MCELROY, M. B. The empirical content of nash-bargained household behavior. Journal of Human Resouces, v. 25, n. 4, p. 559-83, 1990.

MEISELS, S.; LIAW, F. Failure in grade: Do retained students catch up? Journal of Educational Research, v. 87, n. 2, p. 69-77, 1993. 
MENEZES-FILHO, N.; VASCONCELLOS, L.; RIBEIRO, W. S. Avaliando o impacto da progressão continuada no brasil. 2005.

MULLAHY, J. Specification and testing of some modefied count data models. Journal of Econometrics, v. 33, p. 341-365, 1986.

PARO, V. H. Reprovação escolar renúncia a educação. [S.l.]: São Paulo:, 2003.

WOOLDRIDGE, J. M. Econometric analysis of cross section and panel data. [S.1.]: The MIT Press, 2002. 